\title{
Determinants of the Socio-Economic Turnout Gap in OECD Countries
}

\author{
Constantin Manuel Bosancianu*
}

September 26, 2021

\begin{abstract}
Consistent evidence of variation in the participation gap between education or income groups in developing and developed democracies has begun to accrue. This points to varying disparities in participation between the haves and have nots that occasionally reach alarming levels, potentially triggering breakdowns in political representation. A few cross-sectional analyses identify institutional factors, such as voting complexity or state capacity, or economic ones, like income inequality, as driving the difference. Few explanations currently try to address why this participation gap varies over time. This is the question I take up here-I examine the extent to which the turnout gap has changed over time, and what the most robust explanations are for this temporal trend out of a set of factors grouped into 3 "families". These sets of explanations refer to mechanisms that operate through voters' (1) resources, (2) motivation to participate, or (3) likelihood of being mobilized at election time. Using an original pooled data set, with individual-level turnout data from 170-180 elections in 21 OECD countries, and party placement data from the MARPOR project, I show that the magnitude of the turnout gap between lower-SES and higher-SES citizens has increased over time, and that this trend has mainly been driven by the demobilization of lower-SES citizens. A two-stage analysis reveals that union density along with legislative fractionalization are the most consistent correlates of the participation gap between SES groups. The results are obtained from the most comprehensive evaluation to date of the way in which the SES-based turnout gap in advanced democracies has evolved over time. The findings contribute to our understanding of the long-term consequences
\end{abstract}

\footnotetext{
${ }^{*}$ Research fellow, Wissenschaftszentrum Berlin für Sozialforschung, Institutions and Political Inequality research unit. Email: manuel.bosancianu@wzb.eu. Past versions of this paper have been presented at the 2016 IPSA World Congress, Poznán, Poland, and at Freie Universität Berlin. I am grateful to members of the audience at these event for feedback and constructive comments, as well as to Carsten Q. Schneider, Levente Littvay, Gábor Tóka, Zoltán Fazekas, Macartan Humphreys, Bernd Beber, Alexandra Scacco, Swen Hutter, Arndt Leininger, Ana García-Hernández, and Michael Seese. Olga Leshchenko has provided excellent research assistance.
} 
for individual political behavior of institutional transformations in advanced democracies, and the democratic implications of these changes.

\section{Introduction}

Across the majority of advanced industrial democracies, the last four decades have witnessed an almost uninterrupted decline in aggregate voter turnout (Solijonov, 2016). Though the range of channels through which citizens can engage with politicians has also undoubtedly expanded, such a consistent trend nonetheless constitutes a worrying development. Declining rates of electoral participation could be a mark of democratic dissatisfaction and deeper failures of representation. If allowed to persist across a few electoral cycles, they could also produce a cohort of permanently apathetic citizens. Even more concerning, though, is recent evidence that the gap in turnout between socio-economic groups has also grown over the same period in a number of countries (Blais, Gidengil, \& Nevitte, 2004; Dalton, 2017; Schäfer, Roßteutscher, \& Abendschön, 2020; Soss \& Jacobs, 2009). This article seeks an answer to why this latter trend has emerged.

An uneven decline in turnout propensity between politically relevant cleavages represents a clear deterioration of democratic quality and should, therefore, be an area of sustained focus among political scientists. If political parties are primarily responsive to those who are more active and engaged among their electorates (Adams \& Ezrow, 2009), a growing disparity in participation might lead to uneven representation (Lijphart, 1997). Glaring inequalities in participation appear incompatible with claims that political systems are representative and strive to give equal weight to the full spectrum of political opinions in the citizenry. Such disparities could also be a portent of the appearance of anti-system political actors that attempt to take advantage of the silent tide of discontent (Kriesi \& Schulte-Cloos, 2020; Rooduijn, van der Brug, \& de Lange, 2016).

We still possess limited insights about the causes of the socio-economic (SES) participation gap in developing and developed democracies (Dalton, 2017; Fraga, 2018; Gallego, 2015; Matsubayashi \& Sakaiya, 2020). Most of these findings point to relatively stable causes: either features of the political system, such as the degree of clientelism (Amat \& Beramendi, 2016) or ballot complexity (Gallego, 2015), or institutional factors, such as welfare state design (Schneider \& Makszin, 2014), or macroeconomic factors, such as the level of economic inequality (Filetti \& Janmaat, 2018; Huijsmans, Rijken, \& Gaidyte, 2020; Schäfer \& Schwander, 2019). These explanations would suggest that the participation gap is a slow-moving feature of politics, and that we can hope to see any changes in the trend only over a few decades.

While fully acknowledging these factors, the analysis presented here goes beyond them in two important ways. First, it seeks to explain why the turnout gap varies over time as opposed to across countries, as has generally been the case in existing work. This is justified by the potential of 
differential dynamics to be at play across units and time (for the association between inequality and trust, see Fairbrother \& Martin, 2013). Second, it pits in a head-to-head statistical race a large collection of factors which disparate analyses have identified as being associated with the turnout gap. This "horse race" is meant to offer a more robust set of answers regarding the determinants of this gap than past efforts could. As a brief preview of the findings, I find that over time the socio-economic turnout gap has indeed increased over the past five decades in a sample of 21 consolidated democracies. I then turn to a set of 3 "families" of explanations, encompassing factors that exert their effect either through (1) resources individuals use for participation, (2) the motivation to be engaged politically, or (3) the probability of mobilization by a political actor. Of the 3 , the most consistent explanation for changes in the size of this gap refers to mobilization factors, and specifically union strength. From a practical perspective, these conclusions are generated from a large and original data set of individual-level harmonized election surveys from 21 countries, totaling 170-180 elections, and covering a period of 60 years in some cases. I harmonize a select set of variables from these studies, and run a simple turnout model, which produces a simple measure of the SES-based gap in turnout. Via a two-stage modeling strategy, I then relate this gap to a series of theoretically-informed time-varying and time-invariant country-level correlates. In this way, this represents the most comprehensive longitudinal investigation of the turnout gap to date.

The following section organizes the disparate explanations encountered in the literature for the SES-based participation gap into 3 sets of factors, grouped based on the individual-level dynamic they operate through. Following this, I outline two expectations regarding this gap and its drivers, as well as the data sources and methods used to answer my inquiries. The subsequent section presents both descriptive and inferential analyses that tackle the questions I pose, and which show that of the 3 set of explanations, factors that operate through changes in mobilization patterns are most consistently linked to variations in turnout levels between the socio-economic groups. The final section offers a broader interpretation for these results, along with a few concluding thoughts.

\section{The Turnout Differential: Competing Explanations}

Aggregate turnout levels in advanced industrial democracies have received active scrutiny, with studies frequently seeking to explain cross-national variation (Blais \& Dobrzynska, 1998; Endersby \& Krieckhaus, 2008; Radcliff \& Davis, 2000). The insights produced have covered a range of topics, from the strong influence of compulsory voting laws on turnout, to the impact of population size and concurrent elections (for a comprehensive review, see Geys, 2006), and the role played by generational replacement in explaining turnout decline (Franklin, 2004).

The considerable amount of attention awarded to this topic is clearly justified when considering the potential distortions introduced in the mechanism of political representation by unequal turnout 
(Lijphart, 1997). Without a credible threat of electoral punishment elected representatives have little reason to actively inquire about, and follow through on, the preferences of those most likely not to vote (Hajnal \& Trounstine, 2005). The precise characteristics of these citizens vary to an extent from country to country (Amat \& Beramendi, 2020; Kasara \& Suryanarayan, 2015; Matsubayashi \& Sakaiya, 2020). In the United States and a host of other democracies they tend to be those with the lowest income and least amount of education in the citizenry. While stopping short of linking it to participation rates, recent analyses indeed suggest that this income-based pattern of skewed representation is present and very strong (Giger, Rosset, \& Bernauer, 2012; Gilens, 2005). When there is disagreement in preferences between lower- and higher-income voters elected representatives appear to overwhelmingly favor the side of higher-income voters (Gilens, 2012), leading to policies which systematically go against the interests and needs of poorer citizens (Fellowes \& Rowe, 2004). ${ }^{1}$

The matter of whether the gap in participation between various groups defined based on socioeconomic criteria has been growing, diminishing or staying constant over time has received less attention in the literature (but, see Abramson \& Aldrich, 1982; Franklin, 2004; Gallego, 2009; Miller, 1992). While education- and income-based unequal political participation had been observed in the US since the early 1970s (Verba \& Nie, 1972), contemporaneous cross-national investigations had diagnosed Western Europe as unaffected (Barnes \& Kaase, 1979; Topf, 1995).

More recently, we have begun to recognize that this conclusion was premature. Starting with the evidence presented by Burden (2009) for the United States, and by Bovens and Wille (2011) for the Netherlands, there is a growing body of evidence that such a gap, based primarily on education, does indeed exist (for cross-national evidence, see Armingeon \& Schädel, 2015). From establishing the existence of a growing gap in participation, the focus has rapidly changed to explaining what is driving it. The proposed explanations can all trace their roots to a standard model of participation, which sees high rates of turnout as sustained by either resources, motivation, or mobilization (Brady, Verba, \& Schlozman, 1995; Rosenstone \& Hansen, 1993), or by combinations of these factors. I outline each of these in part in the following subsections.

\subsection{The what: resource endowments}

Under the logic of resources, early explanations pointed to the ability of structural factors to shape the resource endowments citizens can draw on in the process of turning out to vote. To begin with, a growing process of individualism has impacted the density of social organizations and social networks that individuals can draw on when voting (Putnam, 2000). Both these structures subsidize the costs of acquiring information about candidates or party platforms. As these costs

\footnotetext{
${ }^{1}$ In a recent contribution, though, Lupu and Warner (2021) fail to find any association between turnout rates and a measure of ideological congruence on a Left-Right axis between citizens and legislatures.
} 
are more burdensome for lower-SES citizens, this weakening of associational life should have a disproportionately negative impact on them, resulting in a greater turnout gap (Armingeon \& Schädel, 2015).

An additional factor subsumed under this logic, but captured from a more static perspective, is the the complexity of the voting procedures, as well as that of the choice environment (Gallego, 2015). Settings where voting rules form a complex set of regulations, or where the governing coalition is comprised of multiple parties, represent a challenge for low-SES voters, who lack the political sophistication to navigate such landscapes unassisted. The same instances impact high-SES voters very little, as the latter possess the requisite levels of political sophistication to cope with this environment. Gallego (2015) tests these propositions, both in a cross-national setting and through an experimental approach, and finds support for them. To take but the first case, the turnout level of lower-educated voters in countries with more demanding ballot structures is lower than in countries without these features. On the other hand, ballot complexity barely influences the turnout level of higher-educated voters (p. 84). Through this dynamic the gap in turnout between educational groups is larger in countries that exhibit a more complex choice environment. A similar dynamic is at play for an aggregate indicator of party dynamics: political polarization (Crepaz, 1990; Muñoz \& Meguid, 2021; Wilford, 2017). Growing polarization of platforms makes it easier for lower educated respondents to differentiate between party platforms, and reduces the cognitive demands of voting, which should be reflected in a more compressed participation gap (but, see Rogowski, 2014).

A final explanation that targets individual resources points to the multiple influences of the welfare state on participatory disparities (Marx \& Nguyen, 2018; Shore, 2014). Institutional arrangements that govern social support and labor protection can have an impact on the participation level of lower educated respondents (Schneider \& Makszin, 2014). By shielding them from large income shocks in the case of job loss, as well as by providing public goods like higher-quality education or support for families with children, a more generous welfare state raises the participation level of lower educated individuals relative to their peers. This is accomplished primarily through an increase in the bundle of material and cognitive resources that can be allocated to participation.

\subsection{The why: willingness to participate}

People also participate in politics because they value the act in itself, and because they believe such participation to be meaningful, important, and consequential for political decisions. The next set of factors that have been proposed as explanations for the participation gap target citizens' motivation for participation.

To begin with, welfare state institutions can also work according to a motivation logic. In 
addition to providing material support, they also offer protection from market forces, and allow lower educated citizens to develop more dense social networks that sustain participation (Abrams, Iversen, \& Soskice, 2011; Schneider \& Makszin, 2014, p. 441). Welfare state policies also convey information about how much the political system values specific sub-groups in the population, and the extent of responsiveness to their concerns (Wichowsky \& Moynihan, 2008). This should thus translate into a narrower gaps in political efficacy and perceptions of responsiveness, which ought to lead to a corresponding reduction in the participation gap (Shore, 2014).

A frequently mentioned factor that operates by altering motivations is economic inequality (Solt, 2008), particularly for participatory acts other than campaign contributions. According to "relative power theory" (Goodin \& Dryzek, 1980), rising economic inequality will lead to shifts in income groups' ability to get their desired political outcome, in a direction that favors wealthier voters. Lower income respondents register this decreased ability to shape political decisions, and correspondingly reduce their involvement in politics. Solt (2008) is among the first to show consistent cross-national evidence to support this dynamic, primarily among advanced industrial democracies. Under conditions of higher economic inequality the gap in political participation or political interest between income groups grows by means of the disproportionate disengagement of poorer voters (Filetti \& Janmaat, 2018; Schäfer \& Schwander, 2019).

Changes in willingness to engage in politics could also be triggered by party dynamics and the political offer closer to the moment of election (Adams \& Merrill III, 2003; Adams, Dow, \& Merrill III, 2006). When candidates or parties move farther away from the ideal policy point of their core constituency, electoral abstention (from alienation and/or from indifference) may ensue. In this instance, the policy proposals advocated by political actors are either too far away from the voter to justify participation or are too similar with each other to justify the effort in making a choice, or both. As Leftist parties in a number of advanced democracies have charted a course toward the center of the political spectrum (Green-Pedersen \& Kersbergen, 2002; Keman, 2011), this could decrease the appeal of their platforms for lower-SES respondents. In turn, this would be converted into a lower rate of participation for these individuals, and a growing SES-based gap in engagement.

\subsection{The how: political mobilization}

The final set of factors exerts an influence by shaping who gets encouraged to participate. In addition to the subjective feeling that participation is not important anymore, given the unappealing policy offerings, lower-class voters are also faced with the issue of mobilization. The first such factor, with a long tradition in empirical analyses, is the strength of labor unions. By encouraging participation, supplying logistical voting day information, and even organizing registration drives, labor unions can exert a potent effect on the participation patterns of lower socio-economic status 
citizens. ${ }^{2}$ Cross-national evidence about the impact of declines in the organizational power of Left parties and unions on turnout is found in the work of Mark Gray and Miki Caul (2000). More direct evidence pertaining to the participation gap comes from Hill and Leighley (1996), Leighley and Nagler (2007), and Wichowsky (2012), who find that increased mobilizational efforts, in particular by the Democrats in the US, produce higher aggregate turnout rates and a lower socio-economic bias in turnout. Gallego (2015, ch. 5) supplements this with cross-national evidence, and shows that at the individual-level union membership is associated with a narrower turnout gap between educational groups, though no similar effect could be uncovered for union density at the aggregate level.

A second correlate of the participation gap that works by altering the mobilization differential between socio-economic groups is the prevalence of electoral clientelism (Amat \& Beramendi, 2020). In contexts of high inequality, where the share of low income voters is greater, mobilization appeals based on material bribes are an optimal strategy for political elites. In such contexts, we are likely to observe a relatively higher level of participation of citizens from lower socio-economic groups (Matsubayashi \& Sakaiya, 2020). A second channel through which the participation gap might be reduced is a growing withdrawal from political life of citizens from higher socio-economic groups, in the face of widespread vote buying and electoral bribes (Huijsmans et al., 2020). In combination, these two dynamics should produce a narrower gap in political engagement, as the studies cited here confirm.

\section{Goals of the Study}

In spite of this wealth of theoretical expectations and separate empirical explorations, only ? (?) has pitted these explanations against each other, in an attempt to understand which of them are most consistently associated with the socio-economic turnout gap. The analysis here draws strongly on this work in pursuing a similar set of questions, though crucially does so in a longitudinal setting, which should partly alleviate concerns about unobserved heterogeneity operating at the between-country level (see Huijsmans et al., 2020). Although Dalton (2017, ch. 9) takes up a similar question, he only describes these longitudinal trends, stopping short of modeling the temporal variation. Finally, to address the paucity of cross-national research on a link between party ideological changes and turnout gaps, this analysis provides the first direct test of whether party dynamics indeed influence the participation gap across time.

I formulate, and test, two main hypotheses:

\footnotetext{
${ }^{2}$ This factor can be placed in more than one category as well. Unions also distill complex policy positions into a simple heuristic (for or against the working (wo)man), as well as endorse specific candidates. Both of these reduce the cognitive burdens of making an electoral choice, and could therefore operate under a resources logic.
} 
- H1: The participation gap between low-SES and high-SES citizens has grown in most advanced industrial democracies over the past five decades.

- H2: Party ideological shifts are associated with the SES-based participation gap, even after controlling for other relevant determinants of disparities in turnout.

Whereas the first hypothesis will be subjected to both a visual test (examining participatory trends and the turnout gap over time) and a statistical one, the latter will only benefit from a statistical test. In the latter case, though, I rely both on a systemic indicator, party polarization, as well as one at the party family level: the ideological shifts of a Left and Right group of parties. At the same time, the benefits of conducting these multivariate analyses go beyond confirming the influence of a single factor. They represent the first comprehensive test of which theoretically-relevant factors are associated with trends in the participation gap among socio-economic groups over time.

\section{Data and Analytic Strategy}

As the focus of my analysis is the gap in the likelihood of participation between groups segmented by socio-economic status, I first obtain estimates of this gap from raw data. I use here a data source produced by harmonizing and merging 206 national election surveys from 22 OECD countries, starting in some cases with the 1950s. ${ }^{3}$ The data has been coded so as to match the unified coding scheme employed in the True European Voter (TEV) project (Schmitt, Önnudóttir, Teperoglou, \& Vegetti, 2013), with the hope of eventually merging the two data sources. ${ }^{4}$ In each of the elections I estimated a reduced model of turnout, using age, a quadratic transformation of age, gender, and a constructed proxy for socio-economic status, based on a respondent's education and income. The education indicator distinguishes between those who have at most a high school degree, and those who have gone to have at least some college education. Income, on the other hand, is measured here using country-specific tertiles into which respondents were fit. This $2 \times 3$ schema produces a 6-point SES classification-dichotomous indicators for the top 5 categories were included in the models. In instances where not all predictors were found in the surveys, or sample sizes for the comparison groups (highest or lowest SES group) were too small, the turnout model was not estimated..$^{5}$ To

\footnotetext{
${ }^{3}$ These countries are: Australia, Austria, Belgium, Canada, Denmark, Finland, France, Germany, Iceland, Ireland, Israel, Italy, Japan, Netherlands, New Zealand, Norway, Portugal, Spain, Sweden, Switzerland, United Kingdom, and the United States.

${ }^{4} \mathrm{~A}$ comprehensive description of the data harmonization procedure, the variable coding, and the final list of countries and elections covered is provided in Sections 1 and 2 of the Online Appendix. No data from the TEV has been used in this analysis, as the TEV has not yet been publicly released.

${ }^{5}$ One of the reasons for which very coarse scales for education and income were preferred was to ensure that the highest and lowest SES groups are of sufficiently large size. Even with such precautions, this was not always the case; in these instances, our estimates had extremely large uncertainty bounds.
} 
correct for the social desirability effects which plague self-reported turnout measures, I computed a weight based on actual VAP turnout in the election, and incorporated this weight in all regressions. Information on official turnout was obtained from the International Institute for Democracy and Electoral Assistance.

\subsection{Modeling approach}

For each election I extract the regression coefficient that refers to high SES respondents (with at least some college education and in the top third of the income distribution). These $\beta$ s quantify the gap in turnout between high SES and low SES respondents - the latter having at most a high school degree and placed in the bottom third of the income distribution. The second stage of this analysis consists of using these coefficients as outcomes in a series of mixed-effects models, with both time-variant and -invariant predictors of the participation gap, which capture phenomena like fluctuations in union density or the number of parties, or institutional features such as compulsory voting laws. As all $\beta$ s extracted in the first stage have an associated measure of uncertainty, all second stage specifications incorporate standard errors from the first stage $\left(S E_{\beta}\right)$, which are used as weights.

The sample on which most models are tested comprises 24 national contexts ${ }^{6}$ and approximately 170-180 elections, varying depending on the specification. All models were run in the Bayesian framework (Gill, 2015), using diffuse Gaussian priors, $\mathcal{N}(0,2.5)$, for all parameters except the intercept, where a prior with a larger variance was used: $\mathcal{N}(0,5)$.

\subsection{Data sources}

The substantive predictors used in the analyses are collated from widely-used data sources (Section 3 of the Online Appendix contains a more detailed description for each indicator). The complexity of the political choice environment is proxied by an index of legislative fractionalization obtained from the Database of Political Institutions (DPI), 2020 version (Cruz, Keefer, \& Scartascini, 2020). This variable denotes the probability that two deputies picked at random from the legislature will be of different parties, and is used under the assumption that more parties place higher cognitive demands on individuals at election time, in terms of information gathering and processing. As a cross-check, I also use here the effective number of parties, which is obtained from the Comparative Political Data Set, 1960-2018 (Armingeon et al., 2020), and is based on the Laakso and Taagepera

\footnotetext{
${ }^{6} \mathrm{~A}$ distinction was made between Flanders and Wallonia in Belgium, due to the different party systems in the respective regions, which produce correspondingly different party competition dynamics. Similarly, I distinguish between Presidential and midterm elections in the United States, given the different patterns of mobilization and stakes of the contests.
} 
(1979) formula, using legislative seats. This is done both as a sensitivity check, as well as to re-test Dalton's (2017, chap. 8) null results with respect to this indicator.

Party polarization is derived from the Comparative Manifestos Project (MARPOR) data, version 2020b (Krause et al., 2020; Volkens et al., 2020), and computed for two dimensions: a standard Left-Right one (RILE), and a secondary one focusing only on socio-economic issues and used as a cross-check on the results. The indicator of polarization is computed as the weighted sum of each party's squared deviation from the weighted average placement on either dimension, where the parties' vote shares are used as weights (Taylor \& Herman, 1971). The main dimension is the standard RILE one, which is directly available in the MARPOR data, and which mixes positions on the economy and welfare state with those on crime, morality, patriotism, or abortion. The secondary dimension, labelled here SOCEC, is solely focused on party stances on the economy (degree of planning and state control), toward the welfare state, as well as toward labor groups in society. Assuming that there are $N$ parties in the system, and that party $i$ 's vote share is $s_{i}$, then the formula for socio-economic polarization is:

$$
\text { Polarization }=\sum_{i=1}^{N}\left(R I L E_{i}-\overline{R I L E}\right)^{2} \times s_{i}
$$

The welfare state characteristic used in this analysis is the degree of generosity of the system, obtained from the Comparative Welfare Entitlements Dataset (CWED), December 2018 version (Scruggs, Jahn, \& Kuitto, 2018). This was preferred over more static typologies (e.g. EspingAndersen, 1990), as it captures changes over time in the actual transfers that the welfare system facilitates. The index incorporates benefits awarded for sickness, loss of employment or retirement, and captures both their level and the ease with which they can be accessed and retained. Economic inequality is proxied with the Gini index of net income inequality, sourced from the Standardized World Income Inequality Database (SWIID), version 9.0 (Solt, 2020). This index ranges from 0 to 100 , where higher values denote a more unequal distribution of incomes in the country. Party ideological shifts are derived from the same source as was used for party polarization: the MARPOR data, and for the same two policy dimensions. I divide parties into a Left camp (Green parties, Socialists/Communists and Social Democrats) and a Right one (Liberals, Christian Democrats, Conservatives, nationalist parties, and agrarian parties); ethnic or regional parties, as well as single-issue parties, are excluded. Separately, for each of these two groups, I compute a weighted placement on both the RILE and the SOCEC dimension, using the vote shares of the parties that comprise each group as weights. ${ }^{7}$

Finally, the strength of the labor movement is proxied with a measure of union density, defined

\footnotetext{
${ }^{7}$ A higher score on the RILE dimension denotes a more Rightward ideological placement, while the same on the SOCEC one denotes a more Leftward one.
} 
as the net union membership as a proportion of wage and salary earners in employment. Information was obtained from Jelle Visser's Database on Institutional Characteristics of Trade Unions, Wage Setting, State Intervention and Social Pacts (ICTWSS), (February 2021). Gallego (2015) shows no impact of union density on the gap in participation between education groups, yet such a counter-intuitive result deserves a second examination, which is why include this measure here. ${ }^{8}$

\section{Results: SES-based Participation Gap}

Thinking back to the summary presented in the literature review section, opinions are still mixed on whether inequality in political participation between SES groups has grown over time. While plenty of evidence points to cross-sectional variation in participatory disparities (Gallego, 2015; Schneider \& Makszin, 2014), temporal variation has mostly been documented in isolated national contexts (but, see Armingeon \& Schädel, 2015). Descriptively, the test I offer here follows in the footsteps of Dalton's (2017, chap. 9) examination of the education-based gap, but relies here on a sample of 22 countries and more than 200 elections, as compared to no more than 10 countries and 103 elections in previous examinations (Dalton, 2017, p. 178). In terms of approach, by pooling disparate explanations for the socio-economic turnout gap and pitting them against each other, the analysis here is closest to Gallego's (2015) efforts. Both pursue a better-specified model of the aggregate-level drivers of participatory disparities. A crucial distinction between the two analyses, however, is the present focus on longitudinal dynamics of the socio-economic turnout gap in consolidated democracies up to this moment. ${ }^{9}$ As the reader can see in the following sections, this has implications for the associations we uncover.

\subsection{Has the gap grown?}

Before presenting the multivariate evidence, though, a rough look at the data offers some clues as to the dynamics I refer to. Below I plot over time the $\beta$ s from the country regressions which contrast high and low SES voters in terms of their turnout probability. These coefficients capture the effect of socio-economic status on turnout, while controlling for age, squared age, and gender. They should therefore offer a good snapshot of the purely SES-based gap in participation.

In Figure 1 the coefficient for the high-SES (at least some college and in the top $33 \%$ of income earners) dichotomous indicator is depicted with a circle, while the bars represent the $95 \%$ confidence

\footnotetext{
${ }^{8}$ Though union density and income inequality are correlated at a moderately strong -0.54 , the theoretical support both measures receive in terms of their association with turnout rates and the turnout differential warranted their joint inclusion.

${ }^{9}$ In terms of estimation approach, I follow in the footsteps of Kasara and Suryanarayan (2015), though focus here on a more homogeneous sample of wealthy nations.
} 
FIGURE 1: Temporal trends in the turnout gap between socio-economic groups

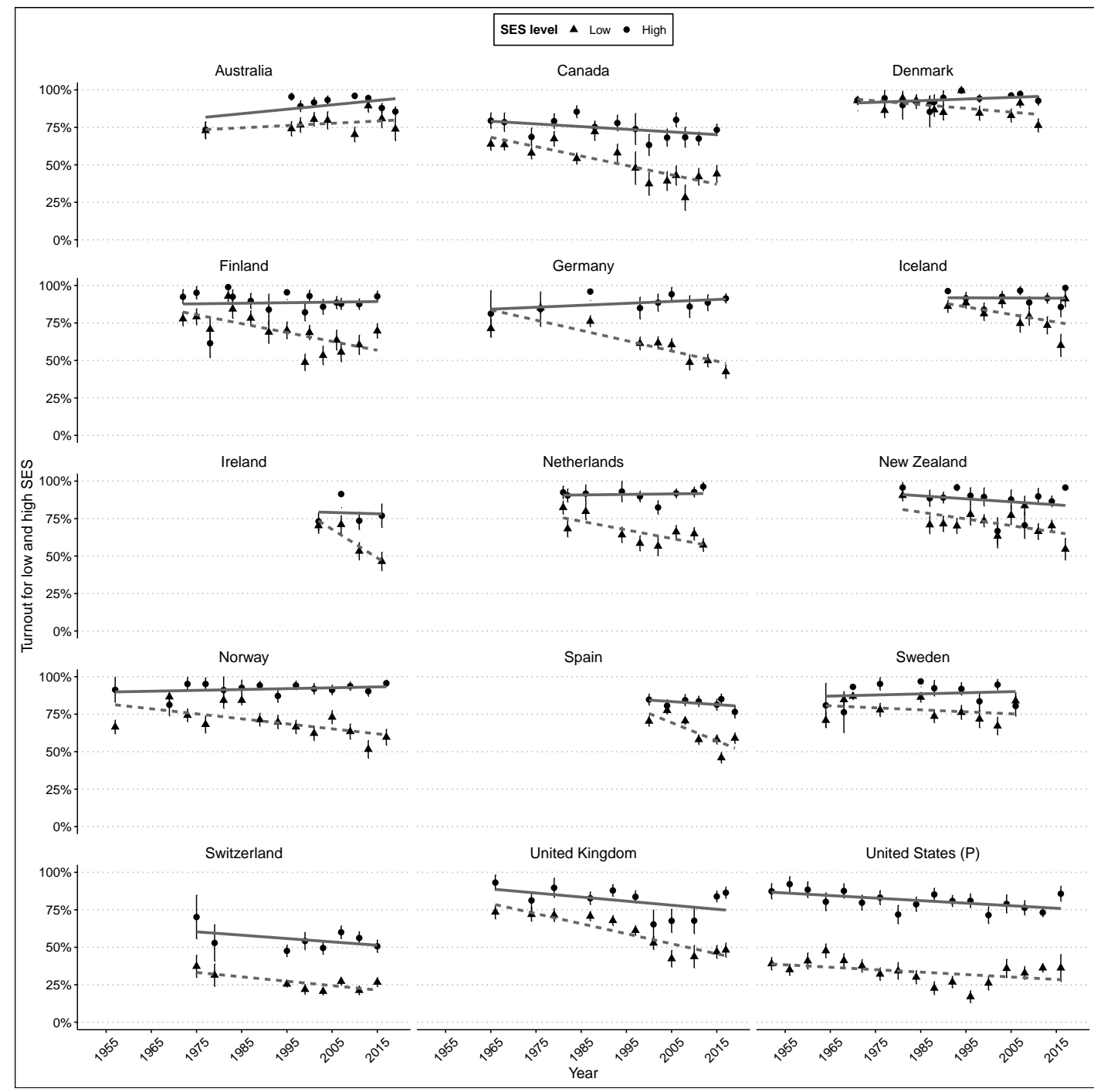

Notes: Points depict the regression coefficient for the high-SES dummy indicator, from a logistic regression specification that controls for age, squared age, and gender. The reference category is low-SES respondents. Vertical bars represent $95 \%$ confidence intervals. A linear fit line (without uncertainty) is superimposed on the panels.

interval for this effect (the reference category is a low-SES respondent: with at most a high-school degree, and in the bottom third of income earners). In 9 of the 15 countries presented in the plot (Canada, Finland, Germany, Iceland, Ireland, Netherlands, Norway, Spain, and the United Kingdom) there is a convincing trend toward a growing disparity in participation. The elections in the latter case are illustrative: though turnout gaps between SES groups in the UK have always existed, the early 1960s and 1970s exhibited differences of roughly 5-15\%. Up to the point Tony Blair assumes the leadership of the Labour Party in 1994, we are presented with largely trendless fluctuation. In the 2000s, though, at which point we can fully speak of Labour as a Third Way party, 
TABLE 1: Longitudinal trends: SES-based turnout gaps

\begin{tabular}{|c|c|c|c|}
\hline & $\begin{array}{c}\text { SES-based } \\
\text { turnout gap }(\beta)\end{array}$ & $\begin{array}{c}\text { Low SES } \\
\text { turnout }(p)\end{array}$ & $\begin{array}{l}\text { High SES } \\
\text { turnout }(p)\end{array}$ \\
\hline (Intercept) & $\begin{array}{c}0.596^{*} \\
(0.185)\end{array}$ & $\begin{array}{r}0.815^{*} \\
(0.046)\end{array}$ & $\begin{array}{r}0.879^{*} \\
(0.029)\end{array}$ \\
\hline Time (in decades) & $\begin{array}{c}0.130^{*} \\
(0.034)\end{array}$ & $\begin{array}{r}-0.042^{*} \\
(0.005)\end{array}$ & $\begin{array}{r}-0.011^{*} \\
(0.004)\end{array}$ \\
\hline$\sigma$ intercept & $\begin{array}{c}0.404^{*} \\
(0.099)\end{array}$ & $\begin{array}{c}0.190^{*} \\
(0.031)\end{array}$ & $\begin{array}{c}0.111^{*} \\
(0.019)\end{array}$ \\
\hline Residual & $\begin{array}{c}0.412^{*} \\
(0.035)\end{array}$ & $\begin{array}{c}0.075^{*} \\
(0.005)\end{array}$ & $\begin{array}{r}0.055^{*} \\
(0.004)\end{array}$ \\
\hline$\rho(\mathrm{AR} 1)$ & $\begin{array}{c}0.419^{*} \\
(0.146)\end{array}$ & $\begin{array}{c}0.354^{*} \\
(0.107)\end{array}$ & $\begin{array}{r}0.285^{*} \\
(0.128)\end{array}$ \\
\hline ELPD & $\begin{array}{r}-168.9^{*} \\
(14.0)\end{array}$ & $\begin{array}{r}222.4^{*} \\
(11.1)\end{array}$ & $\begin{array}{c}260.2^{*} \\
(15.7)\end{array}$ \\
\hline LOO IC & $\begin{array}{c}337.7^{*} \\
(28.1)\end{array}$ & $\begin{array}{r}-444.8^{*} \\
(22.1)\end{array}$ & $\begin{array}{r}-520.5^{*} \\
(31.4)\end{array}$ \\
\hline National contexts & 24 & 24 & 24 \\
\hline Country-years & 206 & 205 & 205 \\
\hline \multicolumn{4}{|c|}{$\begin{array}{l}\text { Method: Specifications are Bayesian mixed-effects models. Flanders and Wallonia in } \\
\text { Belgium were considered two distinct national contexts, due to their different party sys- } \\
\text { tems; Presidential and midterm elections in the US were also considered separately. Re- } \\
\text { sults were produced with the brms package for R (Bürkner, 2017), version } 2.15 \text {.0. Param- } \\
\text { eters are summarized based on a sample of } 15,000 \text { draws from the posterior distribution. } \\
\text { Each model was run using } 3 \text { chains, for a period of } 100,000 \text { iterations, with a burn-in } \\
\text { period of } 95,000 \text { iterations. The models relied on weakly informative priors for the time } \\
\text { effect: } \mathcal{N}(0,2.5) \text {. All models specify an auto-regressive correlation structure (AR1) for } \\
\text { the level- } 1 \text { errors. }\end{array}$} \\
\hline
\end{tabular}

these differences had increased to about 20-25\%. In Germany, the 1960s saw approximate parity in turnout rates between higher and lower SES individuals. Starting with the 1980s we see the manifestation of a gap, which gradually increases to about $50 \%$ in the most recent election in my data; this coincides with the beginning of a sustained decline in union density rates that accelerated even after German Reunification (Fitzenberger, Kohn, \& Wang, 2011). The case of Spain illustrates a similar dynamic, as does that of the Netherlands. Other cases present more subtle and complex patterns. In US Presidential elections we only notice a consistently growing gap in participation rates starting with the late 1960s. This coincides with a move to the economic and cultural Right by the Republican party, potentially fracturing the voting bloc of the working class through the party's emphasis on cultural issues (Frank, 2004), as well as a period of sustained union membership loss (Visser, 2006). ${ }^{10}$

Table 1 provides the first batch of evidence. The first column uses the $\beta$ s from the country-by-

\footnotetext{
${ }^{10} \mathrm{~A}$ few countries have been excluded from the graph. Belgium or Japan have series have series that are too short to discern any trend, while Australia is a country with compulsory voting, where any trend is barely discernible.
} 
country regressions as outcomes in a specification that includes just time (measured in decades). The results provide clear support for the assertion that the SES-based participation gap has worsened over time in advanced industrial democracies (H1). The estimate for time is positive and statistically significant, and denotes that a vulnerable sub-group, comprised of those with lower levels of education and lower income, is withdrawing from the political arena at a higher rate than the rest of the population. The estimate cannot reveal, however, whether the effect of time is of weak or moderate strength (given that it is expressed in the scale of $\beta$ ); neither can it show whether higher SES voters also exhibit decreasing participation rates with the passage of time.

The specifications presented in the next two columns of Table 1 address these shortcomings. They predict the probability of turnout (recorded on a $0-1$ scale) of low SES and high SES respondents. The only predictor used, time measured in decades, quantifies how the turnout propensities of these two groups have changed over time. The most striking implication of the results is that, over time, both groups register a clear decrease in their turnout rates, as seen from the statistically significant coefficients for time in both specifications. The results also offer a more precise dynamic of how the growing SES-based gap in turnout identified in the first column of the table develops over time. Over a decade, more educated and wealthier respondents experience a drop in turnout of, on average, 1.1 percentage points. On the other hand, over a similar period, lower SES citizens exhibit a drop of, roughly, 4.2 percentage points-about 3.8 times greater than that of their higher SES peers.

\subsection{What are the driving factors of this growing gap?}

Having established that the SES-based gap in turnout has indeed grown over time, I now turn to the question of what factors are most consistently associated with the participation dynamics at play between the two SES groups. To answer this I run a set of linear models that include, one by one, the three sets of explanatory factors covered in the theoretical section above, along with a unified specification that includes all sets. All country-year predictors, such as the polarization measures, or income inequality, have been centered around their respective country means (group-mean centering) - their effects now capture only longitudinal variation in the outcome. All specifications also contain two standard controls: compulsory voting and federalism; both have been averaged across years, and included at the country-level. Weakly informative Gaussian priors, $\mathcal{N}(0,2.5)$, were again chosen for all predictors, except the intercepts. Examinations of the income-based or education-based turnout gap have been pursued before, albeit more often cross-sectionally than longitudinally (Gallego, 2015; Dalton, 2017). This analysis is the first to systematically gauge the impact of all major classes of explanations for why this turnout gap varies over time.

Though the analytical setup is unconventional, more akin to a meta-analysis, such an approach 
has clear benefits over alternatives. Past analyses pursue similar questions by means of two-level or three-level mixed-effects specifications, where the crucial estimate comes from a cross-level interaction between a country-level factor and an individual-level indicator of socio-economic status (e.g., Armingeon \& Schädel, 2015). Due to the limited sample size, and the sensitivity of such specifications, the testing is typically done with a limited number of cross-level interactions. My approach, on the other hand, allows the testing of more determinants of the longitudinal turnout gap at the same time. This ability comes at the cost of reduced interpretability, as the outcome is now a coefficient, which makes the units of $\beta$ s largely inscrutable.

Table 2 on page 16 shows the results from these specifications. ${ }^{11}$ The first column probes the resources logic. For both the complexity of the choice environment and party polarization, the results confirm our expectations. As legislative fractionalization increases, so too does the SES-based turnout gap; this dynamic is likely primarily driven by the sensitivity of lower-SES respondents to the cognitive burdens imposed by a highly fragmented party system (Gallego, 2015). Party polarization, on the other hand, exhibits a countervailing effect: growing polarization is associated with a lower turnout gap. As competing platforms become more distinct and, internally, more ideologically consistent, the same cognitive burden experienced by lower-SES voters is diminished. Multiple transmission mechanisms are likely at play. At the same time, a policy that is closer to the ideal point of lower-educated citizens would drive up turnout in this group, as the benefits are greater if Left parties end up in government, as are the losses if these parties do not enter office (Kasara \& Suryanarayan, 2015). Finally, higher polarization is likely correlated with intensified mobilization, which is of greatest importance to lower educated individuals, who thus get access to subsidized political information. Limited variability over time in the index of associational engagement resulted in the need to average this measure over time, and include it at the country-level. Even so, the results presented here suggest it is not associated with the turnout gap, which goes against the findings of Armingeon and Schädel (2015). Overall, though, this class of explanations finds a good measure of support in the data.

The same cannot be said of the second set of explanatory factors, focusing on the motivation to participate, which are presented in the second column of Table 2. Neither income inequality nor party shifts along the RILE dimension appear to be associated with the turnout gap. While the direction for the estimates of both inequality and Left party ideological changes the direction of the estimates conforms to the theoretical expectations, neither is close to conventional levels of significance. In the case of economic inequality the finding does not confirm the effect uncovered by Solt (2008), possibly due to both differences in sample composition and the focus here on longitudinal dynamics. However, it does confirm the null findings of Gallego (2015, chap. 5-6).

\footnotetext{
${ }^{11}$ Basic descriptive statistics for the predictors can be consulted in Section 4 of the Appendix. Due to the very small sample size of 160-200 cases, significance is assessed at the $90 \%$ level.
} 
TABLE 2: Mixed-effects models of the SES-based turnout gap

\begin{tabular}{|c|c|c|c|c|}
\hline & $\begin{array}{c}\text { Resources } \\
\text { logic }\end{array}$ & $\begin{array}{c}\text { Motivation } \\
\text { logic }\end{array}$ & $\begin{array}{c}\text { Mobilization } \\
\text { logic }\end{array}$ & $\begin{array}{r}\text { Unified } \\
\text { model }\end{array}$ \\
\hline Leg. fractionalization & $\begin{array}{c}0.163^{*} \\
(0.105)\end{array}$ & & & $\begin{array}{c}0.118 \\
(0.101)\end{array}$ \\
\hline Polarization (RILE) & $\begin{array}{r}-0.180^{*} \\
(0.098)\end{array}$ & & & $\begin{array}{c}-0.142 \\
(0.134)\end{array}$ \\
\hline Income inequality & & $\begin{array}{c}0.015 \\
(0.111)\end{array}$ & & $\begin{array}{c}-0.045 \\
(0.122)\end{array}$ \\
\hline Left party shifts (RILE) & & $\begin{array}{c}0.095 \\
(0.099)\end{array}$ & & $\begin{array}{c}0.072 \\
(0.132)\end{array}$ \\
\hline Right party shifts (RILE) & & $\begin{array}{c}0.001 \\
(0.101)\end{array}$ & & \\
\hline Union density & & & $\begin{array}{r}-0.220^{*} \\
(0.107)\end{array}$ & $\begin{array}{r}-0.340^{*} \\
(0.130)\end{array}$ \\
\hline Associational engagement & $\begin{array}{c}0.042 \\
(0.232)\end{array}$ & & & $\begin{array}{c}-0.104 \\
(0.252)\end{array}$ \\
\hline Prog. party competition & & & $\begin{array}{c}0.081 \\
(0.197)\end{array}$ & $\begin{array}{c}0.204 \\
(0.238)\end{array}$ \\
\hline Compulsory voting & $\begin{array}{c}-0.405 \\
(0.312)\end{array}$ & $\begin{array}{c}-0.409 \\
(0.289)\end{array}$ & $\begin{array}{c}-0.451 \\
(0.288)\end{array}$ & $\begin{array}{c}-0.377 \\
(0.313)\end{array}$ \\
\hline Federal system & $\begin{array}{c}0.283 \\
(0.251)\end{array}$ & $\begin{array}{c}0.233 \\
(0.200)\end{array}$ & $\begin{array}{c}0.294 \\
(0.193)\end{array}$ & $\begin{array}{c}0.210 \\
(0.256)\end{array}$ \\
\hline (Intercept) & $\begin{array}{l}1.129^{*} \\
(0.105)\end{array}$ & $\begin{array}{l}1.169^{*} \\
(0.094)\end{array}$ & $\begin{array}{l}1.172^{*} \\
(0.093)\end{array}$ & $\begin{array}{l}1.146^{*} \\
(0.102)\end{array}$ \\
\hline$\sigma$ intercept & $\begin{array}{r}0.283^{*} \\
(0.128)\end{array}$ & $\begin{array}{c}0.181^{*} \\
(0.112)\end{array}$ & $\begin{array}{c}0.248^{*} \\
(0.121)\end{array}$ & $\begin{array}{c}0.252^{*} \\
(0.136)\end{array}$ \\
\hline Residual & $\begin{array}{r}0.470^{*} \\
(0.039)\end{array}$ & $\begin{array}{r}0.469^{*} \\
(0.040)\end{array}$ & $\begin{array}{r}0.439^{*} \\
(0.037)\end{array}$ & $\begin{array}{r}0.458^{*} \\
(0.041)\end{array}$ \\
\hline$\rho(\mathrm{AR} 1)$ & $\begin{array}{r}0.528^{*} \\
(0.130)\end{array}$ & $\begin{array}{c}0.569^{*} \\
(0.109)\end{array}$ & $\begin{array}{c}0.554^{*} \\
(0.121)\end{array}$ & $\begin{array}{c}0.543^{*} \\
(0.127)\end{array}$ \\
\hline ELPD & $\begin{array}{r}-156.4^{*} \\
(12.3)\end{array}$ & $\begin{array}{r}-162.0^{*} \\
(12.8)\end{array}$ & $\begin{array}{r}-168.8^{*} \\
(13.7)\end{array}$ & $\begin{array}{r}-145.1^{*} \\
(12.1)\end{array}$ \\
\hline LOO IC & $\begin{array}{r}312.8^{*} \\
(24.7)\end{array}$ & $\begin{array}{r}324.1^{*} \\
(25.6)\end{array}$ & $\begin{array}{l}337.6 \\
(27.3)\end{array}$ & $\begin{array}{r}290.2^{*} \\
(24.2)\end{array}$ \\
\hline National contexts & 21 & 22 & 23 & 20 \\
\hline Elections & 176 & 182 & 198 & 166 \\
\hline
\end{tabular}

Method: Flanders and Wallonia in Belgium were considered two distinct national contexts, due to their different party systems; Presidential and midterm elections in the US were also considered separately. Results were produced with the brms package for $\mathrm{R}$ (Bürkner, 2017), version 2.15.0. Parameters are summarized based on a sample of 15,000 draws from the posterior distribution. Each model was run using 3 chains, for a period of 100,000 iterations, with a burn-in period of 95,000 iterations. The models relied on weakly informative priors: $\mathcal{N}(0,2.5)$. All models specify an auto-regressive correlation structure (AR1) for the level-1 errors.

Notes: Standard errors in brackets. ' $*$ ' indicates that the $90 \%$ credible interval does not intersect 0. ELPD $=$ expected log posterior density. The "Leave-One-Out" cross-validation information criterion (LOO IC) is the Bayesian counterpart of the AIC, and can be interpreted in the same way, i.e. lower values denote a better model fit.

Though the "relative power theory" (Goodin \& Dryzek, 1980; Solt, 2008) primarily refers to participation disparities between income groups, the findings here on SES-based disparities cast a shadow of doubt on the disproportionately corrosive effect of economic inequality for disadvantaged 
citizens, at least when captured in a longitudinal perspective. This conclusion is reinforced by the absence of a statistically significant effect for inequality on the income-based turnout gap in most of the specifications presented in Section 5 (Table 5) in the Online Appendix. All in all, the results reveal no support for this family of explanations.

Finally, I turn to the last set of factors, referring to mobilization. For union strength I uncover the effect I expect: greater union density is associated with a lower turnout gap between socio-economic groups, which confirms in a cross-national setting the effects obtained in the US by Leighley and Nagler (2007). This dynamic would be expected if unions act as agents of electoral mobilization at election time, as well as subsidizers of political information for lower educated and lower income citizens (Macdonald, 2019). At the same time, this result goes against the findings of Gallego (2015). Similar to the case of associational engagement, there is limited temporal variation for programmatic party competition, which required averaging this indicator across years and including it at the country-level in the specifications. Unfortunately, no significant association with the turnout gap is detected, which could plausibly be due to the sample used here-primarily consolidated democracies with more limited variation on this measure. For this set of explanatory factors, then, only union strength receives clear support in the data.

In the final column of Table 2 I include all predictors tested before, with the exception of Right party shifts, for which the estimate was essentially 0 in the second specification. I designate this the unified model; it is the specification that directly tests which among the previous families of explanations withstands being pitted against all others. The results find clear support for the mobilization family, in the form of union strength: as before, higher union density is associated with a lower gap. Unfortunately, all other estimates in the model are not statistically significant. Though for legislative fractionalization and RILE polarization the estimates maintain their direction, their magnitude is smaller compared to the first model. When considering both the indicator for polarization, as well as that for party ideological shifts, the results in Table 2 reveal that the posited association between party dynamics and the turnout gap (H2) has found very limited support in the data.

When turning also to the country-level controls, the general view is of the lack of association with the SES-based turnout gap. The estimates for neither federalism nor compulsory voting reach conventional levels of statistical significance, even though, in the case of the latter, the magnitude is among the largest in the model. Yet again, the explanation in the case of compulsory voting might be the restricted sample used here, where only Australia, Belgium and Italy are classified as compulsory voting countries. ${ }^{12}$

\footnotetext{
${ }^{12}$ Please see Section 3 in the Online Appendix for why Italy is classified in this manner.
} 


\subsection{Assessing impact on SES groups}

The models presented in Table 2 use as outcome a $\beta$ coefficient, which makes grasping the magnitude of the estimated effects for the predictors difficult. To address this, I re-estimate the unified specification from Table 2 separately for lower-SES and higher-SES turnout (measured on a scale from 0 to 1 ). These results are displayed in Table 3 , as well as used to generate the panels presented in Figure 2.

The results show the differential impact our predictors have on the turnout of the two socioeconomic groups shown here. ${ }^{13}$ The first notable comparison refers to the effect of union density. As expected, unions predominantly work to raise the turnout of lower-SES citizens, as evidenced by the estimated coefficient in Model 4A: $\beta=0.057, S E=0.022$. A similar effect is not seen for higher-SES citizens, which lends confidence to accounts that emphasize the targeted efforts of labor unions (Leighley \& Nagler, 2007). The second notable finding is the disparity in how legislative fractionalization influences participation for the two socio-economic groups. The effect of an increased complexity in the party system is stronger on lower-SES respondents than their higher-SES peers, as they lack the political knowledge to cope with such a changed environment. Though this could not be revealed by the results in Table 2, we now see that both the type of party competition and compulsory voting laws do impact SES groups. However, because their impact is of comparable magnitude the gap in participation between groups was not visibly altered. In neither of the two models in Table 3 is political polarization significant, though the estimated effect is clearly stronger for low-SES respondents.

For a visual overview of how the effects of the key predictors identified by our unified specifications from Table 3, the reader can consult the marginal effects plots presented in Figure 2. Each of the panels presents the impact of a separate predictor on the turnout rates of the low-SES and high-SES group. In all three cases the predictors are allowed to vary from the minimum to the maximum value in the sample. We see in panel 2a that, indeed, with declining union density, turnout primarily decreases for lower-SES respondents. For their higher-SES peers changes in union density appear to make no difference in terms of probability to vote. This greater sensitivity of lower-SES citizens to union density is the dinamic that produces the increase in the turnout gap which the final specification in Table 2 reports. In panel $2 b$ we see a corresponding dynamic for legislative fractionalization, though considerably weaker than in the case of density. Changes in fractionalization appear to only impact lower-SES citizens: a more complex choice environment decreases turnout among this group, though the effect is on the order of 3-4 percentage points in most cases. Both these effects, however, are more muted than the almost mechanical effect that

\footnotetext{
${ }^{13}$ The low-SES group (people with less than a high-school degree and in the bottom third of income earners) comprises $27.7 \%$ of the entire sample, while the high-SES one (at least some college classes and in the top third of income earners) represents $13.7 \%$ of the sample. These represent substantive shares of the population.
} 
TABLE 3: Determinants of low-SES and high-SES turnout (unified specification)

\begin{tabular}{|c|c|c|}
\hline & $\begin{array}{c}\text { Model 4A } \\
\text { DV: low-SES turnout }\end{array}$ & $\begin{array}{c}\text { Model 4B } \\
\text { DV: high-SES turnout }\end{array}$ \\
\hline Leg. fractionalization & $\begin{array}{r}-0.027^{*} \\
(0.016)\end{array}$ & $\begin{array}{r}-0.003 \\
(0.011)\end{array}$ \\
\hline Polarization (RILE) & $\begin{array}{c}0.028 \\
(0.021)\end{array}$ & $\begin{array}{c}0.002 \\
(0.014)\end{array}$ \\
\hline Income inequality & $\begin{array}{c}-0.021 \\
(0.020)\end{array}$ & $\begin{array}{r}-0.024^{*} \\
(0.013)\end{array}$ \\
\hline Left party shifts (RILE) & $\begin{array}{l}-0.005 \\
(0.022)\end{array}$ & $\begin{array}{r}-0.000 \\
(0.015)\end{array}$ \\
\hline Union density & $\begin{array}{r}0.057^{*} \\
(0.022)\end{array}$ & $\begin{array}{c}0.002 \\
(0.013)\end{array}$ \\
\hline Associational engagement & $\begin{array}{c}0.057 \\
(0.062)\end{array}$ & $\begin{array}{c}0.037 \\
(0.036)\end{array}$ \\
\hline Prog. party competition & $\begin{array}{r}0.110^{*} \\
(0.058)\end{array}$ & $\begin{array}{r}0.094^{*} \\
(0.034)\end{array}$ \\
\hline Compulsory voting & $\begin{array}{r}0.246^{*} \\
(0.074)\end{array}$ & $\begin{array}{r}0.102^{*} \\
(0.043)\end{array}$ \\
\hline Federal system & $\begin{array}{r}-0.095 \\
(0.063)\end{array}$ & $\begin{array}{r}-0.004 \\
(0.037)\end{array}$ \\
\hline (Intercept) & $\begin{array}{r}0.654^{*} \\
(0.025)\end{array}$ & $\begin{array}{r}0.846^{*} \\
(0.015)\end{array}$ \\
\hline$\sigma$ intercept & $\begin{array}{c}0.078^{*} \\
(0.034)\end{array}$ & $\begin{array}{c}0.061^{*} \\
(0.015)\end{array}$ \\
\hline Residual & $\begin{array}{r}0.085^{*} \\
(0.006)\end{array}$ & $\begin{array}{c}0.054^{*} \\
(0.005)\end{array}$ \\
\hline$\rho(\mathrm{AR} 1)$ & $\begin{array}{r}0.613^{*} \\
(0.113)\end{array}$ & $\begin{array}{c}0.048 \\
(0.148)\end{array}$ \\
\hline ELPD & $\begin{array}{l}170.0^{*} \\
(10.9)\end{array}$ & $\begin{array}{r}202.4^{*} \\
(14.8)\end{array}$ \\
\hline LOO IC & $\begin{array}{r}-340.0^{*} \\
(21.7)\end{array}$ & $\begin{array}{r}-404.8^{*} \\
(29.6)\end{array}$ \\
\hline National contexts & 20 & 20 \\
\hline Elections & 166 & 165 \\
\hline
\end{tabular}

Method: Flanders and Wallonia in Belgium were considered two distinct national contexts; the same goes for Presidential and midterm elections in the US. Results were produced with the brms package for R (Bürkner, 2017), version 2.15.0. Parameters are summarized based on a sample of 15,000 draws from the posterior distribution. Each model was run using 3 chains, for a period of 100,000 iterations, with a burn-in period of 95,000 iterations. The models relied on weakly informative priors: $\mathcal{N}(0,2.5)$. Models specify an auto-regressive correlation structure (AR1) for the level-1 errors

Notes: Standard errors in brackets. ' $*$ ' indicates that the $90 \%$ credible interval does not intersect 0 .

compulsory voting laws have on turnout (panel 2c). While the estimated gap between SES groups in contexts with no compulsory voting laws is approximately 20 percentage points, this narrows down to about 5 points for those with such laws. Though perhaps an unfair comparison to make, this does reveal the limited effect that mobilization or resource factors have on turnout rates. 
FIGURE 2: Effect of key predictors on turnout rates for low- and high-SES groups

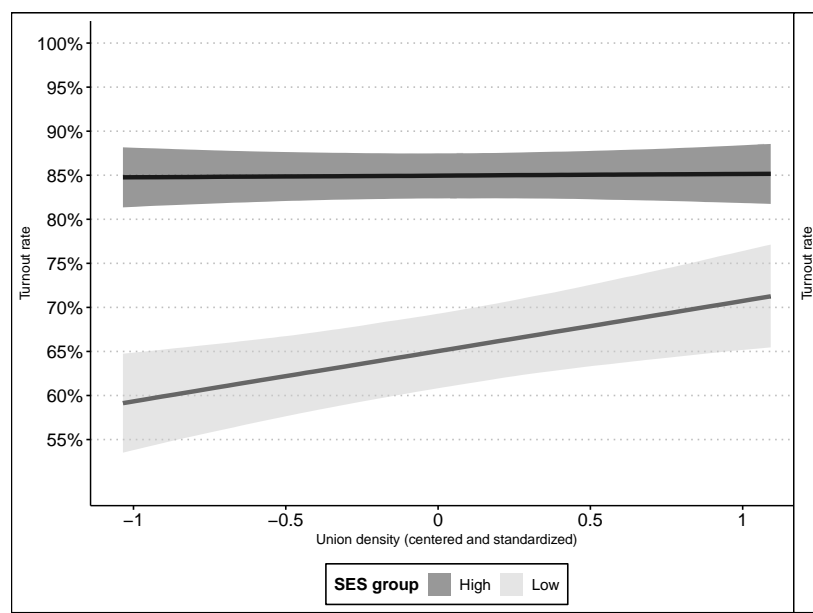

(A) Union density

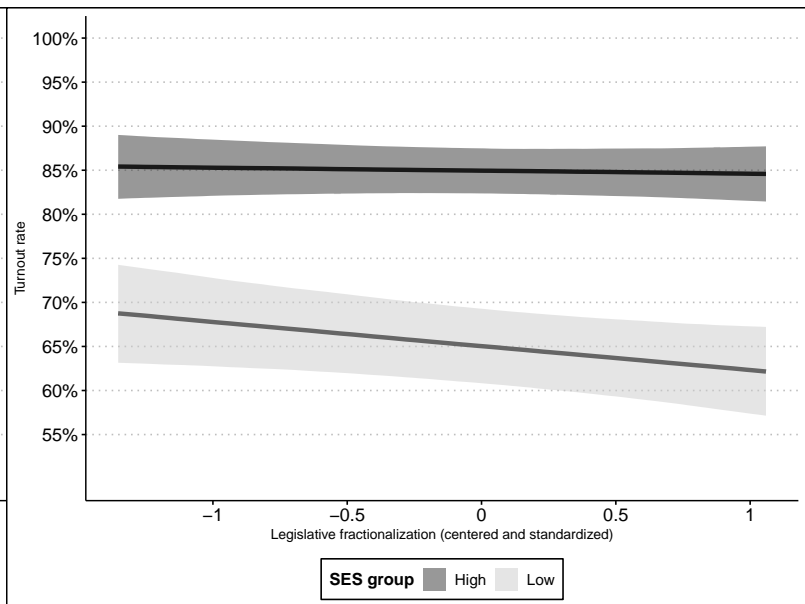

(B) Legislative fractionalization

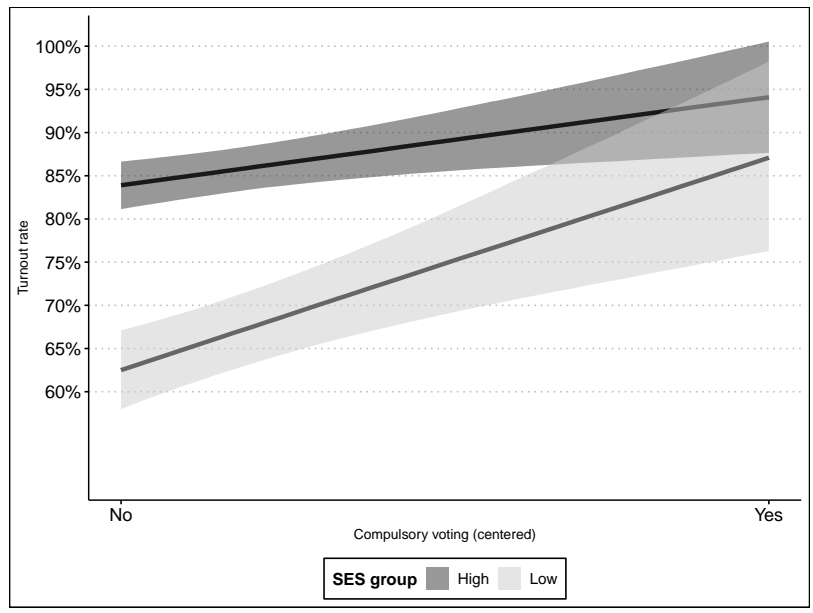

(C) Compulsory voting laws

\subsection{Sensitivity analyses}

A number of sensitivity analyses were performed, and can be consulted in Section 5 of the Online Appendix. For the resources logic, switching to a measure of polarization based on the socio-economic policy dimensions (SOCEC) unfortunately reduces the magnitude of the estimate considerably, though this is still negative (see Table 4 in Section 5). Switching to an alternative indicator of the complexity of the choice environment, the effective number of parties, preserves the magnitude of the effect, but unfortunately not its statistical significance as well. Finally, I also test a model with welfare generosity, included here to control for the effect of welfare state in shaping the resources and mobilization potential of lower-SES citizens (Schneider \& Makszin, 2014). The information is obtained from the Comparative Welfare Entitlements Dataset, December 2018 version (Scruggs et al., 2018). This reduces the sample by about $30 \%$, and does yields an estimate that is not statistically 
significant. In the case of the motivation family of explanations re-estimating the models with the measures of party ideological shifts computed based on placements on the SOCEC dimension yields no change in the substantive conclusions (Table 5 in Section 5). Neither Left nor Right party shifts have any discernible association with the turnout gap.

A number of alternative specifications were tested for the unified specification as well. Switching from legislative fractionalization to the effective number of parties, or from measures of party dynamics based on the RILE dimension to those based on SOCEC, does not change the effect I uncover for union density (Table 6 in Section 5). Neither does adding an indicator for the proportionality of the electoral system: the mean district magnitude. An argument can be made that the variation in the turnout gap we observe is a mechanical effect driven by the overall turnout in the election (an extreme example of this are systems with compulsory voting). To check for this, Models 3 and 4 from Table 6 also include the aggregate VAP turnout rate in the election. The information is obtained from IDEA data (in a few cases, observations were added by hand from Nohlen and Stöver (2010), as well as Adam Carr's Electoral Archive). Though it certainly leads to a decline in the magnitude of the effect of union density, this estimate remains statistically significant, and my substantive conclusions don't change.

To check the sensitivity of the estimates to the choice of a Bayesian procedure, I re-ran all models from Table 2 in a Frequentist setting (see Table 8 in Section 5 of the Online Appendix). The negative effect of union density on the turnout gap is maintained; at the same time, we also see a significant effect of legislative fractionalization, in the expected direction. The goal here is not to adjudicate between the two paradigms (see Elff, Heisig, Schaeffer, \& Shikano, 2021), but to point out that the effect of union strength is robust to a change in estimation approach. Finally, I also try a fixed-effects specification instead of a mixed-effects one (see Table 9). This means that country-level predictors such as compulsory voting, presidential system, or mean district magnitude are excluded from this specification. Yet again, the results with respect to union density remain substantively unchanged, as they do for the remaining set of time-varying predictors.

\section{What Drives the Turnout Gap: Implications}

A number of important points can be extracted from the results presented above. Most worrying for how we evaluate the quality of democratic systems across the OECD is that the turnout gap between socio-economic groups has generally increased over time. Though turnout decline has received extensive coverage (Franklin, 2004; Gray \& Caul, 2000; Kostelka, 2017; Wattenberg, 2000), this growing gap in participation rates between the haves and have nots has received far less attention (but, see Armingeon \& Schädel, 2015; Dassonneville \& Hooghe, 2017; Fraga, 2018). Though its very existence raises important questions of political equality and representation, the 
shape it has taken amplifies the concerns. The worsening gap observed in Figure 1 is primarily due to lower-educated and lower-income citizens dropping out, which signals a democratic deficit and might lead to pockets of support for anti-system political forces.

The more extensive set of findings presented above have focused on what explains temporal changes in this turnout gap. Of the 3 sets of explanations covered by my analyses, the mobilization family is the one that receives the most consistent support, and I refer here specifically to union strength. The findings go beyond an association between union density and turnout (Flavin \& Radcliff, 2011; Gallego, 2010), and point to the disparate impact unions have on socio-economic groups. Union decline is shown to take a greater toll on those citizens who likely rely the most on the cues and information provided by unions. Without the informational and logistical subsidy that unions provide, along with the reinforcement of a shared identity (Brennan \& Hamlin, 1998), lower-educated and lower-income citizens have gradually reduced their political involvement. At the same time, this trend has had no discernible impact on their higher-SES peers.

Though more muted, some support was also found for the resources family of explanations, and particularly for the complexity of the vote choice environment. A higher degree of fractionalization in the legislature increases the turnout gap by mainly reducing the turnout of lower-SES voters. As in the case of union density, higher-SES citizens' turnout appears immune to this dynamic. The result confirms the findings of Gallego (2015) with respect to fragmentation; the plausible mechanism of transmission is the higher cognitive burden on lower-educated voters imposed by such an environment, with multiple political actors taking stances on issues and more potential coalition configurations. Unfortunately, no indication could be found that the remaining factor in this set of explanations, political polarization, also plays a role (judging by the results from the unified specification). In this, my findings partly confirm those of Polacko (2021), who finds no impact of polarization on turnout for either the bottom or top income quintiles in his sample, but partly go against those of Hobolt and Hoerner (2020). Before moving on, though, it's important to point that fractionalization and, to a lesser extent, union density typically have small effects, in the range of a few percentage points of turnout rate for the lower-SES group.

No support could be found for the motivation family, however. Though party dynamics might certainly play a role in turnout in specific national contexts (Elff \& Roßteutscher, 2017), I find no evidence for my larger cross-national sample (see also Kittilson, 2002). This is the case for economic inequality as well, where existing results about the disparate impact of inequality on turnout rates for income groups (Solt, 2008; Lancee \& Van de Werfhorst, 2012) are not replicated here for SES groups. Though my analysis manages to recover a negative effect on the turnout rates of lower- and higher-SES voters (as does that ofPolacko, 2021 for income-based groups), I uncover no influence on the gap between these groups. A reason for this inconsistency might be the sample composition, and my focus on longitudinal dynamics. For my specific group of consolidated 
democracies, the median Gini range over time is only 3.4 units, while the mean is about 4.3 units. $^{14}$ Such limited variation is unlikely to be picked up by even the most attentive voters, and could not plausibly lead to differential responses in the low-SES and high-SES groups.

When considering the frequent accounts of ideological moderation in Leftist parties across a number of OECD countries (Lipset, 2001; Ross, 2008), the (non-)finding related to party dynamics is surprising. A tentative explanation for why no effect is uncovered points to the need for voters to register such platform shifts. Yet results from Adams, Ezrow, and Somer-Topcu (2011) indicate that citizens seem unresponsive to policy pledges made by parties in the campaign period. Multiple dynamics could produce this outcome: other parties and media could cast doubt on a party's promises, voters might resist new information that doesn't fit a party's existing image, or they might allocate a larger weight to parties' past behavior in the legislature (Adams et al., 2011, pp. 371-372). Even if the argument were made that voters register these shifts (Fernandez-Vazquez, 2014), this still would not automatically translate in noticeable changes in individual behavior. Left and Right parties dynamically respond to each other's strategies and ideological movements along multiple policy dimensions, which can result in both de-activation and re-activation of sub-groups of the electorate. Taken together, these might very well produce no visible shift in the participation gap between socio-economic groups.

\section{Conclusions}

The results present here have hopefully convinced the reader of the insights gained from moving beyond examinations of turnout levels toward a greater focus on the turnout gap. Such gaps could be probed along multiple dimensions (gender, age, urban/rural, religious), resulting in potentially fascinating insights regarding the impact of a host of aggregate phenomena, such as policy shifts, changes in descriptive representation, or economic dynamics. I've chosen to focus here on a socio-economic dimension, and my findings have pointed to the importance of mobilization factors, particularly union strength, in explaining temporal variation in the participation rates of lowerand higher-SES groups. In light of the persistent decline in union density that most consolidated democracies have experienced since the 1980s (Vachon, Wallace, \& Hyde, 2016), such a link raises an alarm signal. Lower membership rates impact unions' ability to conduct mobilization campaigns at election time, and to offer logistic support to Left parties during campaigning. With further declines in membership, I expect that this participation gap will only increase.

For every answer provided by my analysis, more than one question is generated. The first concerns the impact of union strength - though suggestive, my data could not speak to the potential impact of changes in parties' mobilization strategies as well. Analyses that could leverage a few

\footnotetext{
${ }^{14}$ The difference is primarily due to Sweden, where the range in Gini is 13.5 points over a period of 42 years.
} 
countries' long election series and items on party contacting, or sub-national data paired with information on party rallies or mobilization efforts, might be able to provide valuable insights into the link between party mobilization and participatory inequality. A second refers to the seeming lack of importance of parties' strategic choices about platforms, which might suggest agency plays little to no role here. Though this comes with methodological challenges of its own, future work could attempt to check whether party positions constructed based on voters' placement of parties, or on expert surveys such as the Chapel Hill one, yields similar conclusions. Finally, throughout the analysis I've treated "Left" or "Right" as a bloc, though this might be too crude of a division. Subsequent efforts could target whether changes in turnout disparity could be produced by dynamics within these blocks, such as the appearance of populist parties on the Right, or the growing strength of the Greens on the Left. In the former case, it is likely that the appearance of parties which combine a traditionalist values agenda with an economic protectionist one might alter the magnitude of this participation gap, though empirical evidence is still missing.

No matter how steep the challenges, the question of what drives participation gaps needs to be pursued further in light of the implications of this phenomenon. Sustained gaps in political engagement could ultimately lead to shifts in the socio-economic platforms put forth by political actors, and in the policies that ultimately get implemented (Fellowes \& Rowe, 2004; Hajnal, 2010). This could produce yet further inequality in resources relevant for political participation, and create a reinforcing cycle of disengagement and growing inequality. 


\section{References}

Abrams, S. A., Iversen, T., \& Soskice, D. (2011). Informal Social Networks and Rational Voting. British Journal of Political Science, 41(2), 229-257.

Abramson, P. R., \& Aldrich, J. H. (1982). The Decline of Electoral Participation in America. The American Political Science Review, 76(3), 502-521.

Adams, J., Dow, J. K., \& Merrill III, S. (2006). The Political Consequences of Alienation-Based and Indifference-Based Voter Abstention: Applications to Presidential Elections. Political Behavior, 28(1), 65-86.

Adams, J., \& Ezrow, L. (2009). Who Do European Parties Represent? How Western European Parties Represent the Policy Preferences of Opinion Leaders. The Journal of Politics, 71(1), 206-223.

Adams, J., Ezrow, L., \& Somer-Topcu, Z. (2011). Is Anybody Listening? Evidence That Voters Do Not Respond to European Parties' Policy Statements During Elections. American Journal of Political Science, 55(2), 370-382.

Adams, J., \& Merrill III, S. (2003). Voter Turnout and Candidate Strategies in American Elections. The Journal of Politics, 65(1), 161-189.

Amat, F., \& Beramendi, P. (2016). Economic and Political Inequality: The Role of Political Mobilization [Working Paper]. Barcelona: Institute of Political Economy and Governance (IPEG). Retrieved from http://www. barcelona-ipeg.eu/wp-content/uploads/2015/ $09 /$ AmatEconPolineqfinal.pdf

Amat, F., \& Beramendi, P. (2020). Democracy under High Inequality: Capacity, Spending, and Participation. The Journal of Politics, 82(3), 859-878.

Armingeon, K., \& Schädel, L. (2015). Social Inequality in Political Participation: The Dark Sides of Individualisation. West European Politics, 38(1), 1-27.

Armingeon, K., Wenger, V., Wiedemeier, F., Isler, C., Knöpfel, L., Weisstanner, D., \& Engler, S. (2020). Comparative Political Data Set, 1960-2018. Bern: Institute of Political Science, University of Bern.

Barnes, S. H., \& Kaase, M. (1979). Political Action: Mass Participation in Five Western Democracies. Beverly Hills, CA: Sage Publications.

Blais, A., \& Dobrzynska, A. (1998). Turnout in Electoral Democracies. European Journal of Political Research, 33(2), 239-261.

Blais, A., Gidengil, E., \& Nevitte, N. (2004). Where Does Turnout Decline Come From? European Journal of Political Research, 43(2), 221-236.

Bovens, M., \& Wille, A. (2011). Diplomatiedemocratie: Over de Spanning Tussen Meritocratie En Democratie. Amsterdam, NL: Bert Bakker. 
Brady, H. E., Verba, S., \& Schlozman, K. L. (1995). Beyond SES: A Resource Model of Political Participation. American Political Science Review, 89(2), 271-294.

Brennan, G., \& Hamlin, A. (1998). Expressive voting and electoral equilibrium. Public Choice, 95(1), 149-175.

Burden, B. C. (2009). The Dynamic Effects of Education on Voter Turnout. Electoral Studies, $28(4), 540-549$.

Bürkner, P.-C. (2017). brms: An R Package for Bayesian Multilevel Models Using Stan. Journal of Statistical Software, 80(1), 1-28.

Crepaz, M. M. L. (1990). The Impact of Party Polarization and Postmaterialism on Voter Turnout: A Comparative Study of 16 Industrial Democracies. European Journal of Political Research, 18(2), 183-205.

Cruz, C., Keefer, P., \& Scartascini, C. (2020). Database of Political Institutions 2020 (DPI2020). Washington, D.C.: Inter-American Development Bank.

Dalton, R. J. (2017). The Participation Gap: Social Status and Political Inequality. New York: Oxford University Press.

Dassonneville, R., \& Hooghe, M. (2017). Voter turnout decline and stratification: Quasiexperimental and comparative evidence of a growing educational gap. Politics, 37(2), 184-200.

Elff, M., Heisig, J. P., Schaeffer, M., \& Shikano, S. (2021). Multilevel Analysis with Few Clusters: Improving Likelihood-Based Methods to Provide Unbiased Estimates and Accurate Inference. British Journal of Political Science, 51(1), 412-426.

Elff, M., \& Roßteutscher, S. (2017). Social Cleavages and Electoral Behaviour in Long-Term Perspective: Alignment without Mobilisation? German Politics, 26(1), 12-34.

Endersby, J. W., \& Krieckhaus, J. T. (2008). Turnout Around the Globe: The Influence of Electoral Institutions on National Voter Participation, 1972-2000. Electoral Studies, 27(4), 601-610.

Esping-Andersen, G. (1990). The Three Worlds of Welfare Capitalism. Cambridge, UK: Polity.

Fairbrother, M., \& Martin, I. W. (2013). Does Inequality Erode Social Trust? Results from Multilevel Models of US States and Counties. Social Science Research, 42(2), 347-360.

Fellowes, M. C., \& Rowe, G. (2004). Politics and the New American Welfare States. American Journal of Political Science, 48(2), 362-373.

Fernandez-Vazquez, P. (2014). And Yet It Moves: The Effect of Election Platforms on Party Policy Images. Comparative Political Studies, 47(14), 1919-1944.

Filetti, A., \& Janmaat, J. G. (2018). Income inequality and economic downturn in Europe: a multilevel analysis of their consequences for political participation. Acta Politica, 53(3), 327-347.

Fitzenberger, B., Kohn, K., \& Wang, Q. (2011). The erosion of union membership in Germany: 
determinants, densities, decompositions. Journal of Population Economics, 24(1), 141-165.

Flavin, P., \& Radcliff, B. (2011). Labor union membership and voting across nations. Electoral Studies, 30(4), 633-641.

Fraga, B. L. (2018). The Turnout Gap: Race, Ethnicity, and Political Inequality in a Diversifying America. New York: Cambridge University Press.

Frank, T. (2004). What's the Matter with Kansas? How Conservatives Won the Heart of America. New York: Henry Holt and Company.

Franklin, M. N. (2004). Voter Turnout and the Dynamics of Electoral Competition in Established Democracies Since 1945. Cambridge, UK: Cambridge University Press.

Gallego, A. (2009). Where Else Does Turnout Decline Come From? Education, Age, Generation and Period Effects in Three European Countries. Scandinavian Political Studies, 32(1), $23-44$.

Gallego, A. (2010). Understanding unequal turnout: Education and voting in comparative perspective. Electoral Studies, 29(2), 239-248.

Gallego, A. (2015). Unequal Political Participation Worldwide. New York: Cambridge University Press.

Geys, B. (2006). Explaining Voter Turnout: A Review of Aggregate-Level Research. Electoral Studies, 25(4), 637-663.

Giger, N., Rosset, J., \& Bernauer, J. (2012). The Poor Political Representation of the Poor in a Comparative Perspective. Representation, 48(1), 47-61.

Gilens, M. (2005). Inequality and Democratic Responsiveness. Public Opinion Quarterly, 69(5), 778-796.

Gilens, M. (2012). Affluence and Influence: Economic Inequality and Political Power in America. New York: Russell Sage Foundation.

Gill, J. (2015). Bayesian Methods: A Social and Behavioral Sciences Approach (Third ed.). Boca Raton, FL: Chapman \& Hall/CRC.

Goodin, R., \& Dryzek, J. (1980). Rational Participation: The Politics of Relative Power. British Journal of Political Science, 10(3), 273-292.

Gray, M., \& Caul, M. (2000). Declining Voter Turnout in Advanced Industrial Democracies, 1950 to 1997: The Effects of Declining Group Mobilization. Comparative Political Studies, 33(9), 1091-1122.

Green-Pedersen, C., \& Kersbergen, K. v. (2002). The Politics of the 'Third Way': The Transformation of Social Democracy in Denmark and The Netherlands. Party Politics, 8(5), $507-524$.

Hajnal, Z. L. (2010). America's Uneven Democracy: Race, Turnout, and Representation in City Politics. New York: Cambridge University Press. 
Hajnal, Z. L., \& Trounstine, J. (2005). Where Turnout Matters: The Consequences of Uneven Turnout in City Politics. The Journal of Politics, 67(2), 515-535.

Hill, K. Q., \& Leighley, J. E. (1996). Political Parties and Class Mobilization in Contemporary United States Elections. American Journal of Political Science, 40(3), 787-804.

Hobolt, S. B., \& Hoerner, J. M. (2020). The mobilising effect of political choice. European Journal of Political Research, 59(2), 229-247.

Huijsmans, T., Rijken, A. J., \& Gaidyte, T. (2020). The Income Gap in Voting: Moderating Effects of Income Inequality and Clientelism. Political Behavior, (forthcoming). doi: 10.1007/ s11109-020-09652-z

Kasara, K., \& Suryanarayan, P. (2015). When Do the Rich Vote Less Than the Poor and Why? Explaining Turnout Inequality across the World. American Journal of Political Science, 59(3), 613-627.

Keman, H. (2011). Third Ways and Social Democracy: The Right Way to Go? British Journal of Political Science, 41(03), 671-680.

Kittilson, M. C. (2002). Declining Voter Turnout in Comparative Perspective: A Result of Converging Party Profiles? American Review of Politics, 23, 355-377.

Kostelka, F. (2017). Does Democratic Consolidation Lead to a Decline in Voter Turnout? Global Evidence Since 1939. American Political Science Review, 111(4), 653-667.

Krause, W., Lehmann, P., Theres, M., Merz, N., Regel, S., \& Weßels, B. (2020). The Manifesto Data Collection: South America. Version 2020b. Berlin: Wissenschaftszentrum Berlinfür Sozialforschung. Retrieved from https://doi.org/10.25522/manifesto.mpdssa .202010

Kriesi, H., \& Schulte-Cloos, J. (2020). Support for Radical Parties in Western Europe: Structural Conflicts and Political Dynamics. Electoral Studies, 65, 102138.

Laakso, M., \& Taagepera, R. (1979). "Effective" Number of Parties: A Measure with Application to West Europe. Comparative Political Studies, 12(1), 3-27.

Lancee, B., \& Van de Werfhorst, H. G. (2012). Income inequality and participation: A comparison of 24 European countries. Social Science Research, 41(5), 1166-1178.

Leighley, J. E., \& Nagler, J. (2007). Unions, Voter Turnout, and Class Bias in the U.S. Electorate, 1964-2004. The Journal of Politics, 69(02).

Lijphart, A. (1997). Unequal Participation: Democracy's Unresolved Dilemma. The American Political Science Review, 91(1), 1-14.

Lipset, S. M. (2001). The Americanization of the European Left. Journal of Democracy, 12(2), 74-87.

Lupu, N., \& Warner, Z. (2021). Why are the Affluent Better Represented Around the World? European Journal of Political Research. doi: 10.1111/1475-6765.12440 
Macdonald, D. (2019). How Labor Unions Increase Political Knowledge: Evidence from the United States. Political Behavior, 1-24. doi: 10.1007/s11109-019-09548-7

Marx, P., \& Nguyen, C. G. (2018). Political Participation in European Welfare States: Does Social Investment Matter? Journal of European Public Policy, 25(6), 912-943.

Matsubayashi, T., \& Sakaiya, S. (2020). Income Inequality and Income Bias in Voter Turnout. European Journal of Political Economy, 101966. doi: 10.1016/j.ejpoleco.2020.101966

Miller, W. E. (1992). The Puzzle Transformed: Explaining Declining Turnout. Political Behavior, 14(1), 1-43.

Muñoz, M. M., \& Meguid, B. M. (2021). Does party polarization mobilize or de-mobilize voters? The answer depends on where voters stand. Electoral Studies, 70, 102279. doi: 10.1016/j.electstud.2021.102279

Nohlen, D., \& Stöver, P. (2010). Elections in Europe: A Data Handbook. Baden-Baden: Nomos.

Polacko, M. (2021). Inequality, policy polarization and the income gap in turnout. Party Politics, 1-16. doi: 10.1177/13540688211011924

Putnam, R. D. (2000). Bowling Alone: The Collapse and Revival of American Community. New York: Simon and Schuster.

Radcliff, B., \& Davis, P. (2000). Labor Organization and Electoral Participation in Industrial Democracies. American Journal of Political Science, 44(1), 132-141.

Rogowski, J. C. (2014). Electoral Choice, Ideological Conflict, and Political Participation. American Journal of Political Science, 58(2), 479-494.

Rooduijn, M., van der Brug, W., \& de Lange, S. L. (2016). Expressing or Fuelling Discontent? The Relationship between Populist Voting and Political Discontent. Electoral Studies, 43, 32-40.

Rosenstone, S. J., \& Hansen, J. M. (1993). Mobilization, Participation, and Democracy in America. New York: Macmillan.

Ross, F. (2008). The Politics of Path-Breaking Change: The Transformation of the Welfare State in Britain and Germany. Journal of Comparative Policy Analysis: Research and Practice, 10(4), 365-384.

Schäfer, A., Roßteutscher, S., \& Abendschön, S. (2020). Rising Start-up Costs of Voting: Political Inequality among First-Time Voters. West European Politics, 43(4), 819-844.

Schäfer, A., \& Schwander, H. (2019). 'Don't play if you can't win': does economic inequality undermine political equality? European Political Science Review, 11(3), 395-413.

Schmitt, H., Önnudóttir, E. H., Teperoglou, E., \& Vegetti, F. (2013). The True European Voter: Micro Data Codebook. Mannheim University: Mannheimer Zentrum für Europäische Sozialforschung.

Schneider, C. Q., \& Makszin, K. (2014). Forms of Welfare Capitalism and Education-Based Participatory Inequality. Socio-Economic Review, 12(2), 437-462. 
Scruggs, L., Jahn, D., \& Kuitto, K. (2018). Comparative Welfare Entitlements Data Set 2, Version 2018-12. University of Connecticut / University of Greifswald. Retrieved from http: / / cwed2.org/

Shore, J. E. (2014). How Welfare States Shape Participatory Patterns. In S. Kumlin \& I. StadelmannSteffen (Eds.), How Welfare States Shape the Democratic Public: Policy Feedback, Participation, Voting, and Attitudes (pp. 41-62). Cheltenham, UK: Edward Elgar.

Solijonov, A. (2016). Voter Turnout Trends around the World (Tech. Rep.). Stockholm: International Institute for Democracy and Electoral Assistance (IDEA). Retrieved from https://www.idea.int/sites/default/files/publications/ voter-turnout-trends-around-the-world.pdf

Solt, F. (2008). Economic Inequality and Democratic Political Engagement. American Journal of Political Science, 52(1), 48-60.

Solt, F. (2020). Measuring Income Inequality Across Countries and Over Time: The Standardized World Income Inequality Database. Social Science Quarterly, 101(3), 1183-1199.

Soss, J., \& Jacobs, L. R. (2009). The Place of Inequality: Non-Participation in the American Polity. Political Science Quarterly, 124(1), 95-125.

Taylor, M., \& Herman, V. M. (1971). Party Systems and Government Stability. The American Political Science Review, 65(1), 28-37.

Topf, R. (1995). Electoral Participation. In H.-D. Klingemann \& D. Fuchs (Eds.), Citizens and the state (pp. 27-51). Oxford: Oxford University Press.

Vachon, T. E., Wallace, M., \& Hyde, A. (2016). Union Decline in a Neoliberal Age: Globalization, Financialization, European Integration, and Union Density in 18 Affluent Democracies. Socius, 2, 1-22.

Verba, S., \& Nie, N. H. (1972). Participation in America: Political Democracy and Social Equality. New York: Harper \& Row.

Visser, J. (2006). Union Membership Statistics in 24 Countries. Monthly Labor Review, 129, 38.

Volkens, A., Burst, T., Krause, W., Lehmann, P., Matthieß, T., Merz, N., ... Zehnter, L. (2020). The manifesto data collection. manifesto project (mrg/cmp/marpor). version 2020b. Berlin: Wissenschaftszentrum Berlin für Sozialforschung. Retrieved from https: / / doi . org / 10.25522/manifesto.mpds.2020b doi: 10.25522/manifesto.mpds.2020b

Wattenberg, M. P. (2000). The Decline of Party Mobilization. In R. J. Dalton \& M. P. Wattenberg (Eds.), Parties Without Partisans: Political Change in Advanced Industrial Democracies (pp. 64-76). New York: Oxford University Press.

Wichowsky, A. (2012). Competition, Party Dollars, and Income Bias in Voter Turnout, 1980-2008. The Journal of Politics, 74(02), 446-459.

Wichowsky, A., \& Moynihan, D. P. (2008). Measuring How Administration Shapes Citizenship: A 
Policy Feedback Perspective on Performance Management. Public Administration Review, 68(5), 908-920.

Wilford, A. M. (2017). Polarization, Number of Parties, and Voter Turnout: Explaining Turnout in 26 OECD Countries. Social Science Quarterly, 98(5), 1391-1405. 


\title{
Supplementary information
}

\author{
Constantin Manuel Bosancianu*
}

September 26, 2021

This document contains additional information connected with the main results presented in the manuscript:

1. the data set harmonization strategy and sources for the individual-level data (see Section 1);

2. the variable recoding performed as part of the analysis (see Section 2);

3. sources for macro-level data (see Section 3);

4. descriptive statistics for the variables used in the models (see Section 4);

5. sensitivity checks for the main analyses (see Section 5);

6. posterior predictive checks for the unified model in Table 2 in the manuscript (see Section 6).

\section{Data Set Creation}

The data set from which country-election coefficients were computed has itself been obtained from national election studies carried out in each of the countries in the sample. Most of the election surveys have been harmonized and/or merged specifically for this analysis-this applies to 18 full election series: Australia, Belgium, Canada, Denmark, Finland, France, Germany, Iceland, Israel, Italy, Netherlands, New Zealand, Norway, Spain, Sweden, Switzerland, United Kingdom, United States. The remaining election surveys have been sourced from a combination of surveys found in waves 1-4 of the Comparative Study of Electoral Systems and waves 1-6 of the World Values Survey and the European Values Survey. The coding scheme I used to merge the series is based entirely on the coding scheme developed by the True European Voter (TEV) project (https://www.mzes.uni-mannheim.de/d7/en/projects/the-true-european-voter-a-strategy-foranalysing-the-prospects-of-european-electoral-democracy-that-includes-the-west). The final goal is to allow interested researchers to merge these two data sources, albeit for a limited set of variables. ${ }^{1}$

In each instance, a few guidelines were used to determine whether an election study could be included in my sample. The data had to contain a turnout question which refers to a national-level

\footnotetext{
* Research fellow, Wissenschaftszentrum Berlin für Sozialforschung, Institutions and Political Inequality research unit. Email: manuel.bosancianu@wzb.eu.

${ }^{1}$ The TEV data has a European focus; it also strives to include voting studies conducted in Central and Eastern Europe. On the other hand, the data used here expands the TEV's OECD coverage, by including countries outside of continental Europe and the UK, such as Australia, New Zealand, or the US.
} 


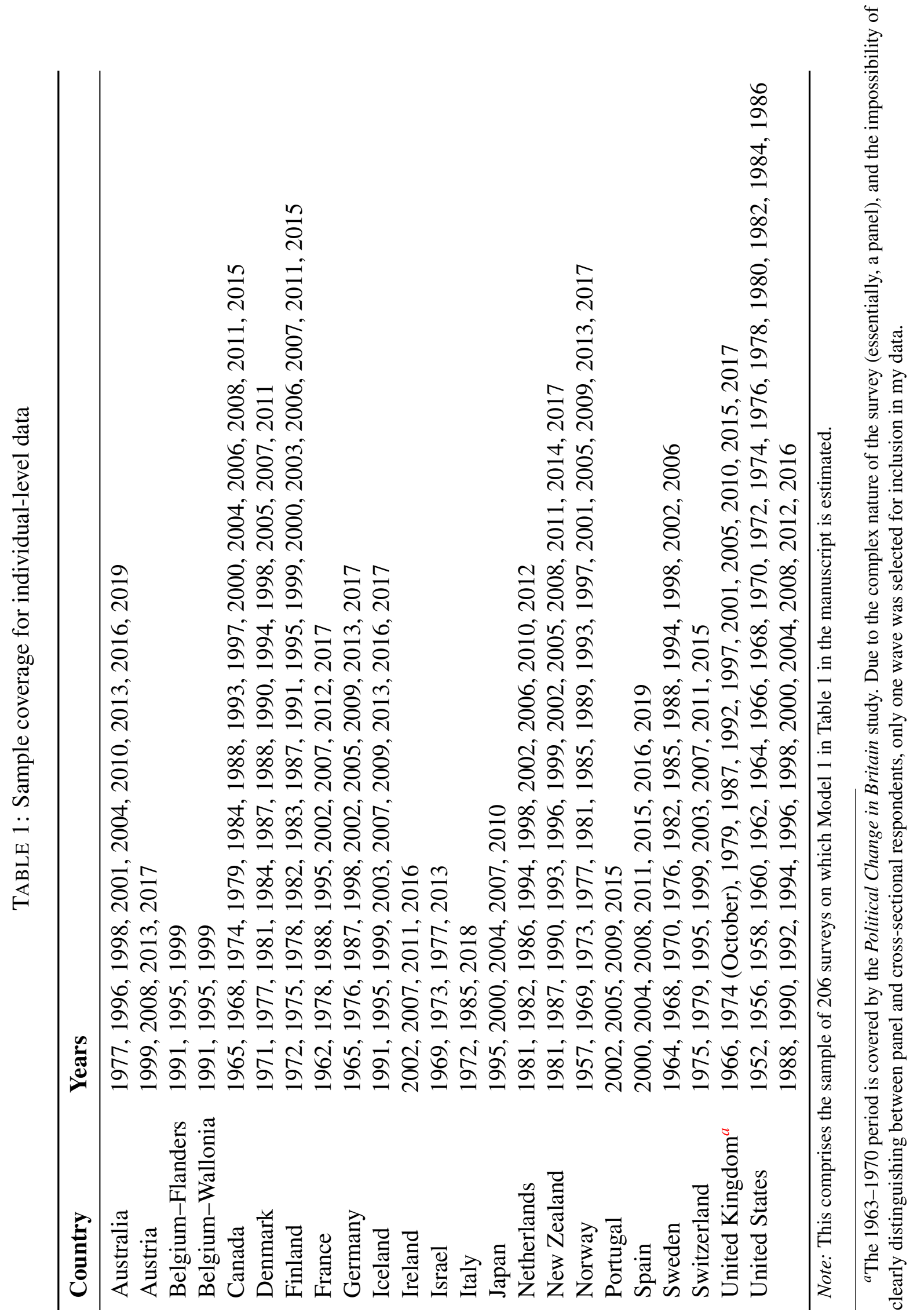


election (either presidential or parliamentary), rather than to a regional one (for regional legislatures or executives). The second criterion refers to the type of sample collected: preference was awarded to cross-sectional samples, rather than to multi-year panels. This is the reason why the 1963-1970 Political Change in Britain survey was reduced to only the 1966 wave. The final criterion refers to timing: post-election surveys were favored. In cases where the election study consisted of a pre-election and post-election component, or was a pre/post panel, only the post-election sample was kept in the data. This was most commonly the case in the Israeli series. If no post-election survey existed, then a pre-election survey was used-in these instances the turnout question was phrased as an intention. Within these constraints the studies presented in Table 1 were accepted for inclusion in the final sample.

When merging the surveys the goal has been to maximize coverage of elections and countries, while maintaining cross-national comparability of the concepts being measured. Deciding whether to consider two items from different surveys as equivalent involved striking a balance between the coverage-comparability trade off mentioned above. Since the national election studies brought together here were not initially implemented with the goal of cross-national comparability in mind, the procedures I have followed (see following section) have resulted in an admittedly patchy data set in terms of missing information.

The following sources have been used for the individual-level data used as part of my analysis:

- Australia: the Australian National Political Attitudes Study, the Australian National Elections Study;

- Austria: World Values Surveys, waves 3-5 of the CSES;

- Belgium: the Belgian National Elections Study;

- Canada: the Canadian National Elections Study;

- Denmark: the 1971-2005 merged file for the Danish Elections Study, the 2007 and 2011 waves of the Danish Elections Study;

- Finland: select years from the Finnish Voter Barometer, the Finnish National Election Study;

- France: the French National Elections Study;

- Germany: the German Federal Elections Series hosted by GESIS (Leibniz Institute for the Social Sciences);

- Iceland: the Icelandic National Election Study;

- Ireland: waves 2-4 of the CSES;

- Israel: the Israeli National Elections Study;

- Italy: the Italian National Elections Study;

- Japan: World Values Surveys, waves 1-4 of the CSES;

- Netherlands: the Dutch Parliamentary Election Study; 
- New Zealand: the New Zealand Election Study, electoral surveys conducted in 1981 and 1987

- Norway: the Norwegian Election Study;

- Portugal: the 2012 Elections, Leadership, and Responsibility study, waves 2-4 of the CSES;

- Spain: Spanish National Election Study;

- Sweden: the Swedish National Election Study;

- Switzerland: the cumulated file 1971-2015 of the Swiss National Election Studies;

- United Kingdom: the 1963-1970 Political Change in Britain study, the British Election Study series;

- United States: 1948-2012 American National Elections Study time series cumulative data file; 2016 ANES Time Series Study.

\section{Individual-level Data: Harmonization}

The guidelines on the basis of which the merging of the data was done have been developed by the TEV project team (Schmitt, Önnudóttir, Teperoglou, \& Vegetti, 2013). They have been followed here as closely as possible, with a view toward ultimately merging the two data sources. The following structure has been maintained, as found in the TEV:

- Age: number of years;

- Gender: 1=female, 2=male;

- Education: 1=primary (complete or incomplete, and incomplete secondary), $2=$ secondary completed, $3=($ at least some) higher education;

- Income: $1=$ lowest tertile, $2=$ middle tertile; $3=$ highest tertile.

Gender and age were the least problematic indicators in the merging process. As would be expected, the scale for gender did not vary between survey series. For age, most surveys recorded age in years; a few chose to record the year of birth, which could easily be transformed into years. In the case of Denmark (1981, 1988 and 1990), Israel (1969 and 1973), Finland (1975, 1983 and 1987), and France (1962 and 2012), age was recorded using distinct categories (usually brackets of 10-15 years). In these instances, no procedure could adequately recover the information lost through using categories. Given that they affect a very small share of the respondents in my data, the solution I adopted here was to recode the categories into the average age of the bracket (e.g. 25-29 was replaced by 27$){ }^{2}$

Education posed a more complex set of problems when it came to processing the different educational levels that exist in the 22 countries into a tripartite division: primary education (including incomplete secondary studies), completed secondary education, and college (including

\footnotetext{
${ }^{2}$ While undeniably problematic, this strategy was considered preferable to losing 10 surveys from the sample.
} 
an incomplete BA degree, and any post-graduate studies). The first difficulty was caused by the issue of vocational education, which doesn't easily fit into this structure. As a general rule, if vocational studies were pursued after lower secondary education (8th or 9th grade), they were considered part of the "secondary incomplete" sub-category. If these studies were taken up after the completion of the secondary cycle, however, as in the German apprenticeship system, they were considered part of the "completed secondary studies" category. ${ }^{3}$ The second difficulty, exhibited by the Australian series, is that the specific items measuring educational achievement do not ask for highest educational level reached, but rather the number of years spent in primary, secondary and tertiary education. On the basis of these a rough categorization could be made.

A more serious complication is the case of Denmark, where it proved impossible to clearly distinguish between those who stopped at a high school degree, and those who chose to continue with a college degree or an apprenticeship. The merged data file for Denmark (1971-2005) places in the same category those with a high school degree and those who went on to college or further. With no remedial measures available, I recoded the " $12+$ years of education" category to designate "some college education". ${ }^{4}$ The case of the United Kingdom illustrates a third problem-the item on education measures the age at which full-time education has been terminated. Having no other course of action available, I recoded education using the 16 and 18 year thresholds. As a rule, 16 or below denotes primary or incomplete secondary education, 17-18 suggests secondary education has been completed, while 19 and above denotes the respondent has at least some college. The 16 years threshold has been chosen under the assumption that those who drop out are more likely to do so at the beginning of the upper secondary cycle (15-16 years) rather than at the end of it, just in sight of high school graduation. Even so, this procedure will surely misclassify individuals who have interrupted their full-time studies and have continued them at a later date.

Income is another indicator which has proven difficult to harmonize across all the studies included here. The TEV project measures income using tertiles, a practice which I have followed here as well. However, even a scale as rough as this posed challenges for the variety of ways in which the income of the household is measured across studies. Where income has been measured in raw currency, this has been a simple procedure (e.g. Norway in 2009, or Canada in 2015). In most other countries, though, income was measured with a ordinal scale, ranging from 7 categories in the Danish 1971 study to 22 in the Australian 2013 one. Additionally, all studies obtained from the CSES measure income in quintiles. With the scale available in the surveys I then proceeded to construct the tertiles as closely as possible to the $33.3 \%$ standard. The outcome has varied. For the 2011 Canadian survey, the tertiles produced have 716, 718 and 710 members, respectively. On the other hand, the best division for Spain in 2011 produced groups of size 1,222, 1,957 and 1,205. Other instances of skewed allocation are France in 1988 (1,573, 1,501 and 541), Italy in 1985 (740, 761 and 233), or New Zealand in 1981 (338, 625 and 481). Thankfully, most countries are

\footnotetext{
${ }^{3}$ The exception here is Finland, where vocational education can extend all throughout college, and results in this case in an applied sciences degree. In these instances, vocational studies pursued at the college level were considered part of the tertiary cycle.

${ }^{4}$ Even when using the individual Danish studies, information about college education doesn't exist prior to 1984. It should be also mentioned that the bias introduced by such coding procedure will be smaller in the case of more recent surveys. As labor market opportunities for high school graduates have diminished, and tertiary education has expanded, a lower share of people in the " $12+$ years of education" category is expected to have only stopped at a high school degree. A 2005 OECD "Education at a Glance" report (OECD, 2005, Graph 1.1a) suggests that about 32\% of people in the 25-64 age category had a college degree in Denmark in 2002. This is not far from the estimate of $30.5 \%$ in the 2001 survey, which includes those with some college as well as everyone above 18 years of age.
} 
in between these two sets of extremes, with deviations of 3-5 percentage points from the standard $33.3 \%$ cutoff.

In addition to the imprecision caused by the uneven group size, other factors also affect the quality of the income measure. Chief among them is the occasional need to include personal income estimates into a series that predominantly refers to household income. A total of 12 election studies use the respondent's income as a measure: Denmark (1971), Finland (1995, 1999 and 2011), New Zealand (1981), Norway (1957), Sweden (1968, 1970, 1994, 1998, and 2006) and the United Kingdom (1966). For a further 4 studies no information about whether the measure refers to personal or household income could be found (Sweden in 1982, 1985, 1988, and 2002). With a continuous income scale and information about the number of adults and children in the household, a rough equivalence could have been established. In their absence, though, no corrective measure could be taken, and the measurements were included in my data as found.

When compared to education and income, the difficulties encountered in joining together the turnout items appear minor in relative terms. With the exception of the United Kingdom 1966 study, all other questions use a simple "yes/no" dichotomous scale for the answer. In the UK case, the item allowed for a "fairly sure voted" option, which was folded into the "definitely voted" category. Refusals to answer or claims of not remembering whether the person voted were coded as "missing". Casting a blank vote was recoded as having turned out in the two studies which included such a response option. Where turnout and vote choice information were part of the same item, a simple recoding procedure compressed this into a dichotomous scale. The more important aspect with regard to turnout is the format of the question-whether it reports a part behavior or a vote intention. The preference has been for past behavior, and the majority of the surveys included in my data report this: only Israel (1973 and 1977) and Japan (2000 and 2010) have items that refer to vote intention. 


\section{Aggregate-level Data}

In this section I offer additional information about the data source and measurement of the main predictors used in the main specifications from the main text and the sensitivity checks presented below. These are grouped based on the logic that governs how their effect on the turnout differential is transmitted.

\subsection{Resources}

Party polarization is based on MARPOR data (Budge, Klingemann, Volkens, \& Bara, 2001; Klingemann, Volkens, Bara, Budge, \& McDonald, 2006; Krause et al., 2020; Volkens et al., 2020), version 2020b. This data set provides the greatest longitudinal coverage of party positions out of all alternatives, and it was primarily for this reason that it was used in my analysis. With a few exceptions (US mid-term elections, the Finnish 2006 and 2015 Parliamentary elections as well as the 1978, 1982 and 2000 Presidential elections, the French 1995 Presidential election, or the Japanese 1995, 2004, 2007, and 2010 contests), all elections covered by my data set have corresponding party placement data in MARPOR. ${ }^{5}$ In the few cases where parties don't have any measurements in the MARPOR data (as their manifesto has yet to be coded), these parties are excluded from the elections they ran in.

Any polarization measure that can be constructed requires an underlying dimension of political conflict along which it can be assessed. For the analyses presented in the manuscript, I rely on the standard RILE indicator available in the MARPOR data. As a cross-check, however, I also compute a summary measure of placement on socio-economic isses (SOCEC) based on the categories listed in Table 2.

First, three scales of support for planned economy (PLAN), support for market economy (MARK), and support for welfare state (WELF) were constructed as seen in Equations 1,2 and 3. They were then used to construct the final socio-economic scale (SOCEC) by subtracting the MARK score from the PLAN and WELF scores, as well as incorporating information about support for specific social groups, as in Equation 3. This broadly follows the practice outlined in Jansen, Evans, and De Graaf (2013, p. 55).

$$
\begin{aligned}
P L A N & =\log (\operatorname{per} 403+0.5)+\log (\operatorname{per} 404+0.5)+\log (\operatorname{per} 405+0.5) \\
M A R K & =\log (\operatorname{per} 401+0.5)+\log (\operatorname{per} 414+0.5) \\
W E L F & =\log (\operatorname{per} 503+0.5)+\log (\operatorname{per} 504+0.5)-\log (\operatorname{per} 505+0.5)
\end{aligned}
$$

For the resulting SOCEC placement a higher score denotes a more Leftward placement of a party. Using party positions on the RILE and SOCEC dimensions I proceeded to aggregate party-level measures into a systemic indicator. The aggregate measure used in the analysis is a party polarization indicator, computed as the weighted sum of each party's squared deviation from the

\footnotetext{
${ }^{5}$ For the Finnish case I used information from the parliamentary elections from 2007, 1979, 1983 and 1999 (no substitution could be made for the 2015 election). Similarly, for the French case, I used the information from the 1993 election, while for the Japanese case I used information from the 1993, 2003, 2005, 2009, and 2012 elections. The short 12-month to 18-month time frame makes it unlikely that parties changed their position considerably between the two time points.
} 
TABLE 2: MARPOR categories used in the construction placement on socio-economic issues

\begin{tabular}{lll}
\hline Category & Item & Meaning \\
\hline \multirow{3}{*}{ Planned economy } & per403 & Market regulation \\
& per404 & Economic planning \\
& per412 & Controlled economy \\
\hline \multirow{2}{*}{ Market economy } & per401 & Free market economy \\
& per414 & Economic orthodoxy \\
\hline \multirow{3}{*}{ Welfare state } & per503 & Equality: positive \\
& per504 & Welfare state: expansion \\
& per505 & Welfare state: limitation \\
\hline \multirow{3}{*}{ Social groups } & per701 & Labor groups: positive \\
& per702 & Labor groups: negative \\
& per704 & Middle class and professional groups: positive \\
\hline
\end{tabular}

weighted average placement on SOCEC or RILE, using the party's vote share $s_{i}$ as weights (Taylor \& Herman, 1971).

The main indicator for the complexity of the political choice environment is legislative fractionalization, obtained from the The Database of Political Institutions (DPI), 2020 version (original variable name is frac) (Cruz, Keefer, \& Scartascini, 2020). This measures the probability that two deputies picked at random from the legislature will be of different parties. Information is missing if there is no parliament, or if there are no parties in the legislature and will be blank if any government or opposition party seats are blank. Manual corrections were required here as well in instances where the information was not available in the DPI: United States (1952, 1956, 1958, 1960, 1962, 1966, 1968, 1970, 1972, 1974, 1976), Australia (2019), Canada (1965, 1968, 1974), Denmark (1971), Finland (1972, 1975), France (1962), Germany (1965, 1976), Israel (1969, 1973), Italy (1972, 2018), Norway (1957, 1969, 1973), Spain (2019), Sweden (1964, 1968, 1970), and the United Kingdom (1966, 1974). I also use, as cross-checks, two alternative proxies for the complexity of the choice environment. The first is a measure of government fractionalization, also obtained from the DPI, 2020 version (original variable name is govfrac). In a similar way to legislative fractionalization, this indicator registers the probability that two deputies picked at random from among the government parties will be of different parties. No manual corrections were performed for this measure. The second proxy is the effective number of parties. This is obtained from the Comparative Political Data Set (CPDS), 1960-2018 (Armingeon et al., 2020), and is based on the Laakso and Taagepera (1979) formula, using legislative seats. Where gaps in the coverage of the CPDS existed I relied on information ${ }^{6}$ produced by Michael Gallagher: Australia (2019), Israel (entire series), Norway (1957), Spain (2019), and the United States (1952, 1956, and 1958).

A final indicator from this set of explanations targets the health of a country's associational life. The measure of associational density used here was obtained from the V-DEM data, version 11.1 (March 2021 - original variable name is v2csprtcpt) (Coppedge et al., 2020). The indicator is

\footnotetext{
${ }^{6}$ Please see https://www.tcd.ie/Political_Science/people/michael_gallagher/ElSystems/Docts/ElectionIndices.pdf [accessed February 5, 2021].
} 
measured on a 4-point scale, ranging from 0 (most associations are state-sponsored and participation in them is not voluntary) to 3 (there is a diverse NGO environment and it's normal for people to be actively involved in at least one). Due to very limited variation over time for the set of countries and time period studied here, this variable is averaged over time for each country in the specifications presented in the Analysis section. Though not reported in the main analysis, a sensitivity analysis also makes use of an indicator for welfare state generosity. This is obtained from the Comparative Welfare Entitlements Dataset (CWED), December 2018 version (Scruggs, Jahn, \& Kuitto, 2018). The index aggregates welfare generosity from three areas: pension, unemployment, and sickness benefits. For each of these dimensions, the index incorporates information about both replacement rates, as well as how strict the eligibility rules are, the coverage of the schemes, and the length of coverage. Higher values on this index denote a more generous welfare state. For all countries, information covers the 1971-2002 period.

\subsection{Motivation}

A core indicator in this set of explanations targets the extent of economic inequality, and the proxy used here is the Gini index of net income inequality, taken from the Standardized World Income Inequality Database (SWIID), version 9.0 (Solt, 2020). Using a combination of lowess, a regression-based imputation model, and a final stage that involves a moving-average smoothing of the estimation, version 9.0 of SWIID (released in October 2020) produces over 5,600 estimates of income inequality. The imputation procedure also generates estimates of uncertainty for these values, which reflect natural imprecision about the "true" level of inequality in a country year. In a few instances the SWIID did not have observations for the elections in my data. One standard example is a missing 1979 observation for Switzerland, with measurement starting only in 1980. In this case and a few similar others, not wishing to discard an entire survey, I plugged in a Gini value assuming a constant rate of growth from year to year. I compute the average rate of growth for the closest consecutive years for which there is data, and use it to derive a predicted measure for the missing year. In the case of Switzerland this meant computing the yearly change rate between 1980 and 1985 and using it, together with the 1980 Gini value, to produce a prediction for 1979. A second typical instance is a yearly series which contains gaps; as in the case of union density above, I plugged in these gaps by hand by assuming a constant rate of change from year to year. In total, 8 such values were computed by myself: Australia (2019), Canada (1968), Iceland (1991 and 2017), Italy (2018), New Zealand (1981), Norway (1969), and Switzerland (1979).

A second set of measures in this category refers to the ideological shifts of parties. As the dynamics between party shifts and participation have made specific reference to Left and Right parties, I grouped parties in each country into a "Left" and "Right" block, based on their ideological family. Ecological, socialist and social-democratic parties have been cataloged as parties of the Left, while liberal, Christian-democratic, conservative, nationalist and agrarian parties have been classified as parties of the Right. Ethnic or regionalist parties, and special issue movements have been excluded from the outset. For each party cluster I use the MARPOR data mentioned above to compute a cluster's ideological placement as the weighted average placement of the parties comprising it, using party vote shares as weights. This is done for both the RILE dimension found in the MARPOR data, as well as the SOCEC one I construct. 


\subsection{Mobilization}

An important indicator in this category is union strength, which was proxied here by union density; this is defined as the net union membership as a proportion of wage and salary earners in employment. Information was obtained from the OECD's Database on Institutional Characteristics of Trade Unions, Wage Setting, State Intervention and Social Pacts (ICTWSS), (February 2021). ${ }^{7}$ In a few instances the yearly series contained gaps, which were plugged in by hand by assuming a constant rate of change from year to year (similar to the case of income inequality above). For 3 years in the Israeli series $(1969,1973$, and 1977) information was not available in this version of the data, and had to be brought in from version 6.1. The 2016 density value had to be used for France in 2017; similarly, the 2018 value was used for Australia in 2019. In total, such manual corrections and imputations were used for 14 out of the 206 surveys listed in Table 1.

Though the availability of information on electoral clientelism is gradually improving, no source with a sufficient longitudinal coverage was available. As a rough proxy, I relied in this analysis on an indicator of the most common form of linkages between parties and voters; this is obtained from version 11.1 of the V-DEM data (original variable name is v2psprlnks). The measure attempts to assess whether parties offer voters specific goods (clientelism) or policy promises (programmatic competition) in exchange for their support at election time. The variable is recorded on a 5-point scale, ranging from 0 (constituents receive cash, goods, or jobs in exchange for support) to 4 (parties offer national policies encoded in party programs). Due to the limited longitudinal variation in this measure for my sample of countries and years, I aggregate this measure by computing country averages across all available years.

\subsection{Additional indicators}

A set of additional indicators have been included as controls in all the specifications tested here. At the country level, information on compulsory voting was added from the data base maintained by the International Institute for Democracy and Electoral Assistance (IDEA). This particular data source does not distinguish between different intensities with which compulsory voting is enforced in the legal system of the country. A few corrections were made by hand in Japan for the years where IDEA coverage was lacking: 1995, 2004, 2007, and 2010. My series for Italy contains both elections that were run under compulsory voting laws, and those run after these laws were abolished. As the majority of observations for Italy are of the former type, it was classified as a compulsory voting country. A dummy indicator for whether the country has a federal system or not was also included. This information was obtained from the CPDS 1960-2018 (original variable name is fed). The original indicator uses 3 categories, but for the purposes of my analysis "weak" and "strong" federalism were collapsed in a single category.

The limited sample size at the country level (only 22 countries) made the inclusion of additional predictors in the main statistical models difficult. However, in the sensitivity checks below I add two additional indicators. The first is a measure of the proportionality of the electoral system: the mean district magnitude for the lower house. Information is obtained from the DPI, version 2020 (original variable name is $\mathrm{mdmh}$ ). The measure is computed as the "weighted average of the number of representatives elected by each constituency size" (Cruz et al., 2020, p. 16). In a few cases, information had to be computed by hand and plugged in: a number of years for Australia,

\footnotetext{
${ }^{7}$ See .
} 
United States, and the United Kingdom, along with Canada (1965, 1968, and 1974), France (1962), Finland (1972), Italy (1972), Norway (1969 and 1973), and Sweden (1968 and 1970). ${ }^{8}$ To control for the mechanic effect that a very high turnout rate has on the SES-based turnout gap, I also test a specification that includes a measure of VAP turnout. This is also obtained from the IDEA turnout data base (https: / / www. idea. int/data-tools/data/voter-turnout). In the case of two years from Japan (2007 and 2010) information was not available in the IDEA data and had to be manually plugged in from the records maintained by the International Foundation for Electoral Systems (IFES).

\footnotetext{
${ }^{8}$ Information generally came from the IPU PARLINE records.
} 


\section{Descriptive Statistics for Variables}

I present here a set of descriptive statistics for the variables used in the statistical specifications in the main text (Table 3). The descriptives for the SES-based turnout gap are based on the sample used in the specifications reported in Table 1 in the main text: 22 countries and 206 elections. The descriptives for the theoretical predictors of interest and the controls are based on the sample used in the models in Table 2 in the main text: 20 countries and 166 elections.

FIGURE 1: Distribution of the SES-based turnout gap

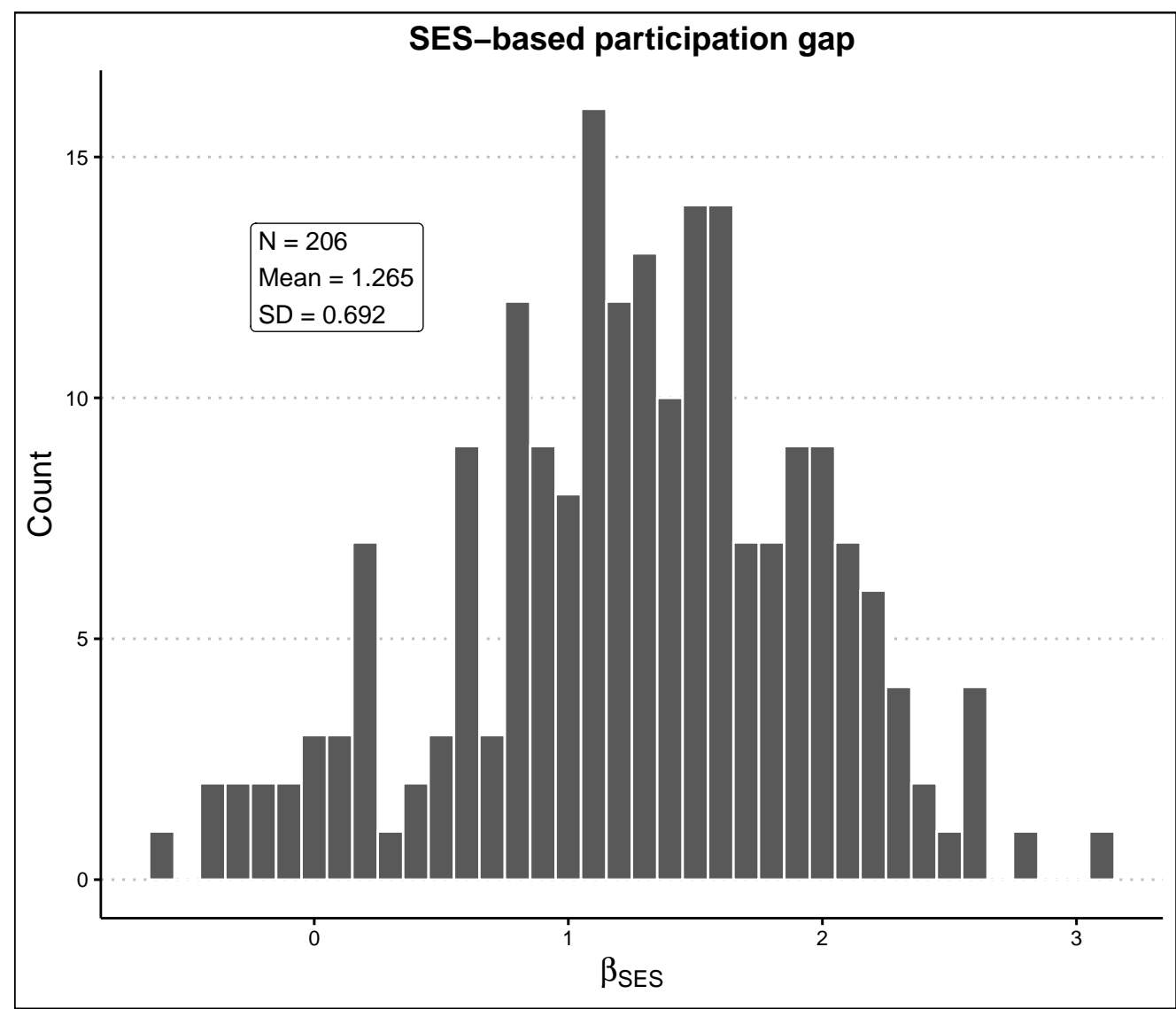

Note: The histograms depict raw logistic regression coefficients quantifying the turnout gap between SES groups: first income tertile and no high school degree vs. third income tertile and at least some college. Regressions also control for age and gender, and incorporate weights to adjust for over-reporting of turnout.

Figure 1 depicts the distribution of the outcome used in the main analysis and in the specifications presented in the Appendix. In spite of a few outliers, the distribution looks relatively Gaussian. It's important to point out that the distribution is considerably shifted to the right with reference to 0 . This denotes that, historically, higher SES voters have almost always participated at higher rates compared to their peers, at least in the context of the consolidated democracies of Western Europe (Matsubayashi \& Sakaiya, 2020).

The most striking aspect of Figure 2 is the moderately-strong correlation over time between union density and income inequality in my sample (Pearson's $\rho=-0.54$ ). This makes it difficult to accurately estimate the independent effect of both of these predictors on the turnout gap. Given that 
TABle 3: Descriptive statistics for predictors

\begin{tabular}{lrrrrrrr}
\hline Variable & Mean & SD & Median & Min. & Max. & Skew & Kurtosis \\
\hline Union density & 39.40 & 22.21 & 31.30 & 10.30 & 86.60 & 0.54 & -1.12 \\
Gini index & 28.50 & 4.26 & 28.50 & 20.50 & 38.30 & 0.10 & -0.86 \\
Leg. fractionalization & 0.68 & 0.11 & 0.69 & 0.41 & 0.90 & -0.24 & -0.85 \\
RILE polarization & 51.11 & 33.24 & 42.89 & 2.31 & 162.06 & 0.99 & 0.60 \\
Left party shifts (RILE) & -6.42 & 5.02 & -6.20 & -19.53 & 4.82 & -0.17 & -0.24 \\
Programmatic linkages & 2.53 & 0.71 & 2.63 & 0.51 & 3.59 & -0.72 & 0.24 \\
Compulsory voting & 0.10 & 0.30 & 0.00 & 0.00 & 1.00 & 2.71 & 5.38 \\
Federalism & 0.36 & 0.48 & 0.00 & 0.00 & 1.00 & 0.57 & -1.68 \\
NGO popular engagement & 1.99 & 0.93 & 1.66 & -0.24 & 3.52 & 0.19 & -0.58 \\
\hline
\end{tabular}

Note: The sample used to produce descriptive statistics (166 elections and 20 countries) is the one used in the unified model from Table 2 in the manuscript.

both income inequality (Solt, 2008) and union strength (Leighley \& Nagler, 2007) are frequently associated in theoretical work with changes in the turnout gap between income or educational groups, and that their effects are hypothesized to operate via different channels, I opted to keep both in the unified specifications presented in the manuscript. 
FIGURE 2: Correlogram for main predictors in the specifications used in main text

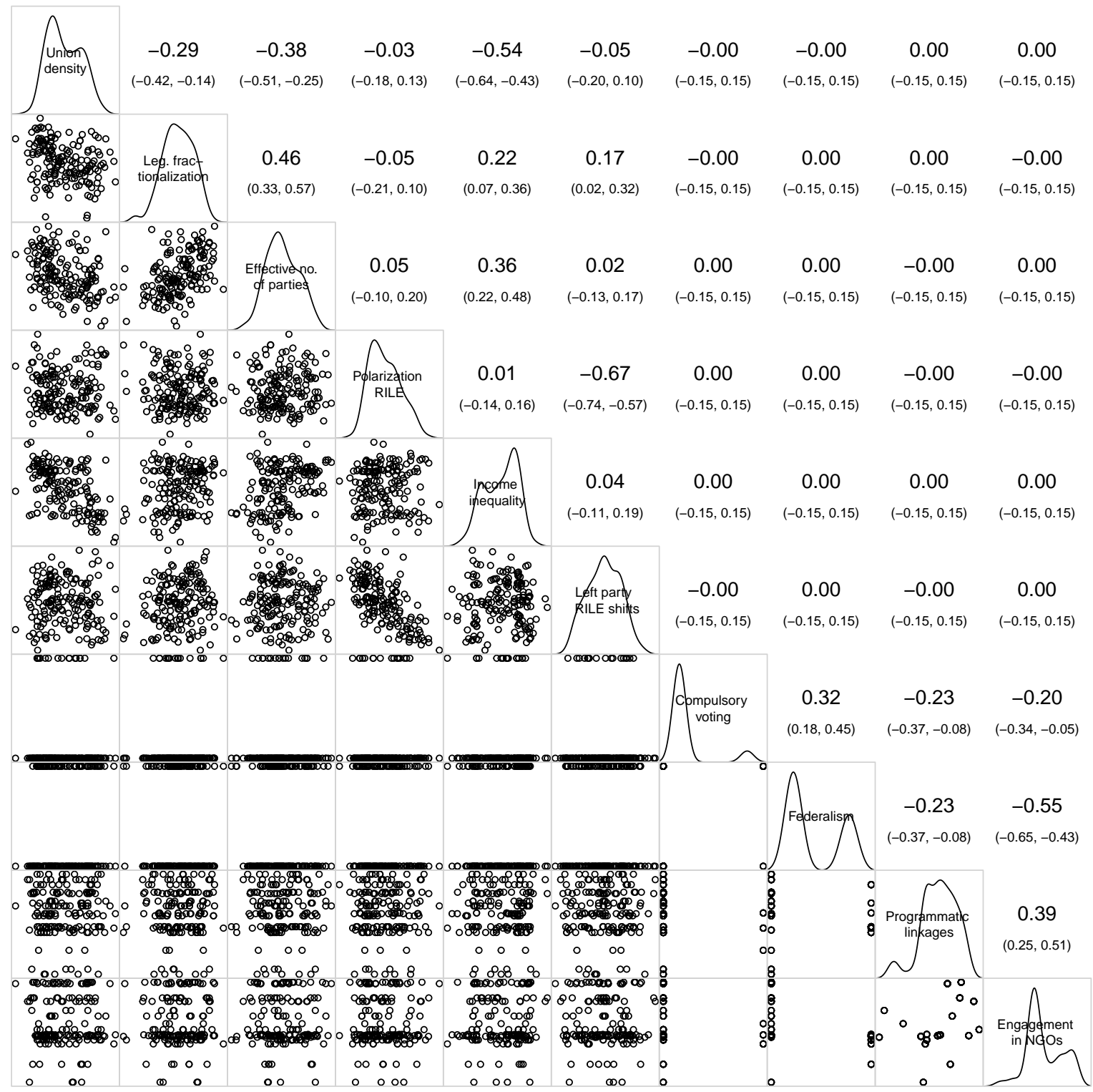

Note: The sample used here comprises 182 elections, from 22 national contexts. This is the same sample on which the results in Model 6 from Table 3 in the main text have been obtained. Lower diagonal panels depict scatterplots, while upper diagonal ones depict Pearson product moment correlation coefficients. Diagonal panels present density plots for the variables. 


\section{Sensitivity Checks for Analyses of SES-based Turnout Gaps}

A number of additional specifications were tested in order to assess the robustness of the findings from the main analysis. The results are structured based on the three broad classes of explanations I outline in the manuscript.

\subsection{Resources logic}

To cross-check the results obtained with the RILE indicator, I re-run the "resources" specification using party polarization based on the SOCEC dimension. As a reminder, this dimension focuses exclusively on party positions on economic issues and the state's involvement in this domain of governance, and is computed based on the same MARPOR data used for the RILE index (Model 1 in Table 4). A second specification checks the effect obtained for legislative fractionalization with an alternative proxy for the complexity of the political choice environment: the effective number of parties. Information about this number is taken from the Comparative Political Data sets, 1960-2018, 2020 version (Armingeon et al., 2020) (Model 2 in Table 4). ${ }^{9}$ Finally, I also test the resources logic with an indicator for welfare state generosity taken from the Comparative Welfare Entitlements Dataset, 2018 version (Scruggs et al., 2018) (Model 3 in Table 4). This indicator for generosity takes into account both differences in replacement rates, as well as coverage, and the strictness of the qualifying conditions for three programs: unemployment benefits, sick pay benefits, and pensions. Due to the limited availability of data on welfare generosity, this indicator was not used for the models reported in the main manuscript.

The results primarily point to stability. In Model 1, substituting SOCEC for RILE as a dimension of party competition does not alter the magnitude of the impact of the complexity of the choice environment on the turnout gap. Contexts with more choices are indeed associated with a larger gap. On the other hand political polarization (based on the SOCEC dimension) is no longer significantly associated with the turnout gap. Though the estimate is still negative, its magnitude drops considerably compared to the effects reported in the main analysis. In Model 2, switching our measure of the complexity of the choice environment does not impact the effect of RILE polarization. However, the effective number of parties is not statistically significant in this specification, though the magnitude of its effect is very similar to that of legislative fractionalization. In Model 3, adding welfare generosity to the specification reduces the sample size by close to a third, and leads to the loss of significance for the effects of both polarization and choice complexity.

\subsection{Motivation}

In the motivation set of explanations, I check whether replacing the RILE dimension of competition with the SOCEC one when computing party ideological shifts over time impacts the substantive conclusions that can be drawn (Model 1 in Table 5 on page 17). As before, a second sensitivity check involves including welfare generosity as an alternative explanation, even at the cost of a reduced sample size (Model 2 in Table 5).

\footnotetext{
${ }^{9}$ Where gaps existed in this data, additional information was brought in from the data produced by Michael Gallagher: https://www.tcd.ie/Political_Science/people/michael_gallagher/Elsystems/ Docts/ElectionIndices.pdf.
} 
TABLE 4: Sensitivity checks for resources logic

\begin{tabular}{lccc}
\hline & Model 1 & Model 2 & Model 3 \\
\hline Leg. fractionalization & $0.171^{*}$ & & 0.141 \\
Effective no. of parties & $(0.097)$ & & $(0.115)$ \\
& & 0.165 & \\
Polarization (SOCEC) & -0.076 & $(0.105)$ & \\
& $(0.095)$ & & \\
Polarization (RILE) & & $-0.201^{*}$ & -0.034 \\
& & $(0.099)$ & $(0.033)$ \\
Welfare generosity & & & 0.104 \\
& & & $(0.112)$ \\
Associational engagement & 0.037 & 0.034 & 0.117 \\
Compulsory voting & $(0.235)$ & $(0.236)$ & $(0.282)$ \\
& -0.392 & -0.396 & -0.389 \\
Federal system & $(0.322)$ & $(0.308)$ & $(0.409)$ \\
& 0.279 & 0.288 & 0.439 \\
(Intercept) & $(0.257)$ & $(0.252)$ & $(0.320)$ \\
& $1.128^{*}$ & $1.132^{*}$ & $1.134^{*}$ \\
$\sigma$ intercept & $(0.109)$ & $(0.105)$ & $(0.125)$ \\
Residual & $0.270^{*}$ & $0.299^{*}$ & $0.260^{*}$ \\
$\rho$ (AR1) & $(0.133)$ & $(0.125)$ & $(0.158)$ \\
& $0.475^{*}$ & $0.468^{*}$ & $0.433^{*}$ \\
ELPD & $(0.040)$ & $(0.040)$ & $(0.050)$ \\
LOO IC & $0.555^{*}$ & $0.490^{*}$ & $0.629^{*}$ \\
& $(0.123)$ & $(0.143)$ & $(0.153)$ \\
\hline National contexts & $-157.3^{*}$ & $-157.8^{*}$ & $-108.8^{*}$ \\
& $(12.0)$ & $(12.2)$ & $(10.3)$ \\
& $314.7^{*}$ & $315.7^{*}$ & $217.7^{*}$ \\
& $(24.0)$ & $(24.4)$ & $(20.6)$ \\
\hline & 21 & 21 & 19 \\
& 176 & 176 & 123 \\
\hline
\end{tabular}

Method: Flanders and Wallonia in Belgium were considered two distinct national contexts, due to their different party systems; Presidential and midterm elections in the US were also considered separately. Results were produced with the brms package for R (Bürkner, 2017), version 2.15.0. Parameters are summarized based on a sample of 15,000 draws from the posterior distribution. Each model was run using 3 chains, for a period of 100,000 iterations, with a burn-in period of 95,000 iterations. The models relied on weakly informative priors: $\mathcal{N}(0,2.5)$. All models specify an auto-regressive correlation structure (AR1) for the level-1 errors.

Notes: Standard errors in brackets. ' $*$ ' indicates that the $90 \%$ credible interval does not intersect 0 . ELPD $=$ expected log posterior density. The "Leave-One-Out" cross-validation information criterion (LOO IC) is the Bayesian counterpart of the AIC, and can be interpreted in the same way, i.e. lower values denote a better model fit.

Model 1 presents the results with SOCEC party shifts. The impact of income inequality on the turnout gap remains very small and not statistically significant, while the effect of party dynamics for either Left or Right parties continues to be indistinguishable from 0 . In Model 2, the consequences 
TABLE 5: Sensitivity checks for motivation logic

\begin{tabular}{|c|c|c|}
\hline & Model 1 & Model 2 \\
\hline Income inequality & $\begin{array}{r}-0.012 \\
(0.114)\end{array}$ & $\begin{array}{c}0.082 \\
(0.122)\end{array}$ \\
\hline Left party shifts (SOCEC) & $\begin{array}{c}-0.027 \\
(0.096)\end{array}$ & \\
\hline Right party shifts (SOCEC) & $\begin{array}{c}0.121 \\
(0.103)\end{array}$ & \\
\hline Left party shifts (RILE) & & $\begin{array}{r}0.146^{*} \\
(0.086)\end{array}$ \\
\hline Right party shifts (RILE) & & $\begin{array}{c}0.027 \\
(0.107)\end{array}$ \\
\hline Welfare generosity & & $\begin{array}{c}0.093 \\
(0.105)\end{array}$ \\
\hline Compulsory voting & $\begin{array}{c}-0.404 \\
(0.286)\end{array}$ & $\begin{array}{c}-0.362 \\
(0.371)\end{array}$ \\
\hline Federal system & $\begin{array}{c}0.240 \\
(0.197)\end{array}$ & $\begin{array}{c}0.363 \\
(0.251)\end{array}$ \\
\hline (Intercept) & $\begin{array}{r}1.166^{*} \\
(0.094) \\
\end{array}$ & $\begin{array}{r}1.157^{*} \\
(0.112)\end{array}$ \\
\hline$\sigma$ intercept & $\begin{array}{r}0.185^{*} \\
(0.113)\end{array}$ & $\begin{array}{r}0.249^{*} \\
(0.144)\end{array}$ \\
\hline Residual & $\begin{array}{r}0.466^{*} \\
(0.040)\end{array}$ & $\begin{array}{r}0.423^{*} \\
(0.047)\end{array}$ \\
\hline$\rho(\mathrm{AR} 1)$ & $\begin{array}{r}0.564^{*} \\
(0.112)\end{array}$ & $\begin{array}{r}0.591^{*} \\
(0.161)\end{array}$ \\
\hline ELPD & $\begin{array}{r}-162.7^{*} \\
(12.8)\end{array}$ & $\begin{array}{r}-107.8^{*} \\
(10.3)\end{array}$ \\
\hline LOO IC & $\begin{array}{r}325.3^{*} \\
(25.6)\end{array}$ & $\begin{array}{r}215.5^{*} \\
(20.7)\end{array}$ \\
\hline National contexts & 22 & 20 \\
\hline Elections & 182 & 126 \\
\hline
\end{tabular}

Method: Flanders and Wallonia in Belgium were considered two distinct national contexts, due to their different party systems; Presidential and midterm elections in the US were also considered separately. Results were produced with the brms package for R (Bürkner, 2017), version 2.15.0. Parameters are summarized based on a sample of 15,000 draws from the posterior distribution. Each model was run using 3 chains, for a period of 100,000 iterations, with a burn-in period of 95,000 iterations. The models relied on weakly informative priors: $\mathcal{N}(0,2.5)$. All models specify an auto-regressive correlation structure (AR1) for the level-1 errors.

Notes: Standard errors in brackets. ' $*$ ' indicates that the $90 \%$ credible interval does not intersect 0. ELPD = expected log posterior density. The "Leave-One-Out" crossvalidation information criterion (LOO IC) is the Bayesian counterpart of the AIC, and can be interpreted in the same way, i.e. lower values denote a better model fit.

of adding welfare generosity, and thus reducing the sample size, are limited to increasing the magnitude of the effect of Left party shifts. Compared to the results presented in the main analysis, this effect is now statistically significant at the $90 \%$ level. Left party shifts toward the center of the 
political spectrum are associated with an increase in the turnout gap, though this conclusion rests on shaky foundations given the reduced sample size.

\subsection{Unified model}

The next set of specifications slightly alters the "unified model" presented in the manuscript. First, Model 1 in Table 6 on page 20 cross-checks the main results by using an alternative proxy for choice complexity. Relying on the effective number of parties does not change the main conclusions at allthe sole predictor that is statistically significant remains union density. Model 2 in Table 6 replaces the predictors that tap into party dynamics based on the RILE dimension with alternative versions based on the SOCEC dimension. This has a minimal impact on the estimates presented; though effect magnitudes change slightly, the lack of statistical significance of the remaining predictors apart from union density is maintained. Model 3 from the table checks for the possibility of a mechanical effect of high turnout. Due to a natural ceiling effect, elections with higher turnout would display a lower turnout gap between SES groups (an extreme example of this are systems with compulsory voting). The results presented in this specification confirm the assumption: the coefficient on VAP turnout is negative and statistically significant. However, even under this stringent test, the negative effect of union density remains significant $(\beta=0.272, S E=0.130, p<.05)$, though its magnitude is reduced. The final model in Table 6 removes 2 predictors at the country level that never displayed a statistically significant effect (engagement in NGOs and programmatic party-voter linkages), and adds a control for the proportionality of the electoral system: the mean district magnitude. Because these is only limited variability in this indicator over time, it is used here as an average of all yearly values of each country in the sample. The results do not change in a substantive way: both union density and VAP turnout have a negative and statistically significant effect on the turnout gap. In this specification, though, the effects of both compulsory voting and federal system are significant. As expected, compulsory voting is associated with a lower turnout gap, while having a federal system is linked to a larger turnout gap.

A last set of Bayesian specifications is presented in Table 7 on page 21. These are based on Model 4 in Table 6, to which I add, sequentially, an indicator of political corruption as well as an indicator of societal polarization. Both are obtained from V-DEM data, version 11.1. The latter (original variable name is v2x_corr) assesses the extent of political corruption in the country, and includes separate measures of 6 different types of corruption, covering the major branches of government: executive, legislative, and judicial. Higher values on this index denote greater pervasiveness of corruption. The second indicator (original variable name is v2cacamps) assesses the extent of societal polarization - the degree to which society is split into antagonistic political camps. The measure is recorded on a 5-point scale, ranging from 0 (denoting that opposing political camps essentially display no animosity toward each other) to 4 (interactions between these opposing camps are generally hostile). Given that for both indicators there is only limited variation over time in the scores, these are averaged across all available years in each country, and included in the multilevel specifications at the country-level. Results from the estimations are presented below.

Including these two new predictors again does not change the conclusions substantively. In both Models 5 and 6 from Table 7 union density and VAP turnout continue to be negative and statistically significant. Compulsory voting and federalism tend to be more unstable when it comes to crossing the threshold of significance. Even so, the magnitude of the estimates for these two variables is relatively similar between the two models. Unfortunately, neither the estimate for 
political corruption nor that for societal polarization is significant in these specifications.

\subsection{Frequentist estimates for main models}

In an attempt to check whether the pattern of results identified so far is a result of the Bayesian approach used, I re-estimated all specifications presented in Table 2 in the manuscript in a Frequentist paradigm. I continue to rely on mixed-effects model, with a first-order auto-regressive correlation structure (AR1) for the level-1 errors. All models were estimated using the Ime() function from the nlme package, version 3.1-152; the inverses of the standard errors of the first-stage coefficients quantifying the turnout gap between high- and low-SES were used as weights. The estimates are presented in Table 8 on page 22 .

The results in the table largely confirm those from Table 2 in the manuscript. A notable difference is the loss of statistical significance for union density in Model 3 (the mobilization specification), though the estimate returns to significance in Model 4 (the unified specification), just as in the main analysis. The second difference is that legislative fractionalization is now statistically significant in the unified specification, but was not in the main analysis in the corresponding model. These differences are minute in comparison to the similarities between the two sets of results, with significance largely preserved and the direction of effects identical.

\subsection{Fixed-effects specifications for main models}

In the final set of specifications in this section, presented in Table 9 on page 23, I test the robustness of the mixed-effects specifications presented so far by means of a set of fixed-effects specifications. Though the possibility of unobserved between-country heterogeneity biasing the estimates of timevarying predictors (such as union density or income inequality) is addressed by using within-cluster centering, I nevertheless present here these slightly more robust specifications. I use country dummies in all specifications, though choose not to present their estimates in the tables below, in the interest of brevity. The consequence of this is that country-level predictors such as compulsory voting, federalism, PR electoral system or associational engagement cannot be included in the specifications. I use again Bayesian estimation with diffuse priors, and specify a first-order autoregressive structure, $\operatorname{AR}(1)$, for the residuals. The models are again estimated with the help of the brms package, version 2.15.0 (Bürkner, 2017).

The results are similar here as well to those presented in the main analysis, both in terms of the effect of legislative fractionalization in the resources specification, as well as that of union density in the mobilization and unified specifications. For party polarization in the resources specification

the estimate is not statistically significant, yet it has the same sign and a comparable magnitude to the estimate reported in the main analysis. 
TABLE 6: Sensitivity checks for unified specification

\begin{tabular}{|c|c|c|c|c|}
\hline & Model 1 & Model 2 & Model 3 & Model 4 \\
\hline Leg. fractionalization & & $\begin{array}{c}0.136 \\
(0.101)\end{array}$ & $\begin{array}{c}0.079 \\
(0.100)\end{array}$ & $\begin{array}{c}0.084 \\
(0.095)\end{array}$ \\
\hline Effective no. of parties & $\begin{array}{c}0.085 \\
(0.106)\end{array}$ & & & \\
\hline Polarization (RILE) & $\begin{array}{c}-0.142 \\
(0.136)\end{array}$ & & $\begin{array}{r}-0.130 \\
(0.133)\end{array}$ & $\begin{array}{r}-0.160 \\
(0.118)\end{array}$ \\
\hline Polarization (SOCEC) & & $\begin{array}{r}-0.087 \\
(0.170)\end{array}$ & & \\
\hline Income inequality & $\begin{array}{r}-0.059 \\
(0.124)\end{array}$ & $\begin{array}{r}-0.048 \\
(0.125)\end{array}$ & $\begin{array}{r}-0.081 \\
(0.120)\end{array}$ & $\begin{array}{r}-0.110 \\
(0.107)\end{array}$ \\
\hline Left party shifts (RILE) & $\begin{array}{c}0.089 \\
(0.135)\end{array}$ & & $\begin{array}{c}0.075 \\
(0.133)\end{array}$ & $\begin{array}{c}0.006 \\
(0.117)\end{array}$ \\
\hline Left party shifts (SOCEC) & & $\begin{array}{c}-0.017 \\
(0.170)\end{array}$ & & \\
\hline Union density & $\begin{array}{r}-0.346^{*} \\
(0.131)\end{array}$ & $\begin{array}{r}-0.360^{*} \\
(0.136)\end{array}$ & $\begin{array}{r}-0.272^{*} \\
(0.130)\end{array}$ & $\begin{array}{r}-0.265^{*} \\
(0.117)\end{array}$ \\
\hline VAP turnout & & & $\begin{array}{r}-0.252^{*} \\
(0.114)\end{array}$ & $\begin{array}{r}-0.262^{*} \\
(0.108)\end{array}$ \\
\hline Associational engagement & & $\begin{array}{c}-0.106 \\
(0.249)\end{array}$ & $\begin{array}{c}-0.096 \\
(0.242)\end{array}$ & \\
\hline Prog. party competition & $\begin{array}{c}0.195 \\
(0.231)\end{array}$ & $\begin{array}{c}0.202 \\
(0.235)\end{array}$ & $\begin{array}{c}0.202 \\
(0.227)\end{array}$ & \\
\hline Compulsory voting & $\begin{array}{r}-0.375 \\
(0.310)\end{array}$ & $\begin{array}{r}-0.370 \\
(0.312)\end{array}$ & $\begin{array}{r}-0.380 \\
(0.305)\end{array}$ & $\begin{array}{r}-0.432^{*} \\
(0.259)\end{array}$ \\
\hline Federal system & $\begin{array}{c}0.219 \\
(0.252)\end{array}$ & $\begin{array}{c}0.213 \\
(0.255)\end{array}$ & $\begin{array}{c}0.226 \\
(0.249)\end{array}$ & $\begin{array}{r}0.350^{*} \\
(0.189)\end{array}$ \\
\hline Mean dist. magnitude & & & & $\begin{array}{c}0.248 \\
(0.173)\end{array}$ \\
\hline (Intercept) & $\begin{array}{r}1.148^{*} \\
(0.102)\end{array}$ & $\begin{array}{r}1.145^{*} \\
(0.104)\end{array}$ & $\begin{array}{r}1.146^{*} \\
(0.102)\end{array}$ & $\begin{array}{r}1.166^{*} \\
(0.086)\end{array}$ \\
\hline$\sigma$ intercept & $\begin{array}{r}0.262^{*} \\
(0.132)\end{array}$ & $\begin{array}{c}0.238^{*} \\
(0.134)\end{array}$ & $\begin{array}{c}0.273^{*} \\
(0.130)\end{array}$ & $\begin{array}{c}0.235^{*} \\
(0.107)\end{array}$ \\
\hline Residual & $\begin{array}{c}0.458^{*} \\
(0.042)\end{array}$ & $\begin{array}{c}0.464^{*} \\
(0.042)\end{array}$ & $\begin{array}{c}0.448^{*} \\
(0.041)\end{array}$ & $\begin{array}{c}0.440^{*} \\
(0.038)\end{array}$ \\
\hline$\rho(\mathrm{AR} 1)$ & $\begin{array}{r}0.516^{*} \\
(0.134)\end{array}$ & $\begin{array}{c}0.562^{*} \\
(0.120)\end{array}$ & $\begin{array}{c}0.495^{*} \\
(0.146)\end{array}$ & $\begin{array}{r}0.421^{*} \\
(0.151)\end{array}$ \\
\hline ELPD & $\begin{array}{r}-146.6^{*} \\
(12.2)\end{array}$ & $\begin{array}{r}-146.8^{*} \\
(11.6)\end{array}$ & $\begin{array}{r}-144.9^{*} \\
(12.3)\end{array}$ & $\begin{array}{r}-155.3^{*} \\
(12.7)\end{array}$ \\
\hline LOO IC & $\begin{array}{r}293.2^{*} \\
(24.5)\end{array}$ & $\begin{array}{c}293.5^{*} \\
(23.2)\end{array}$ & $\begin{array}{r}289.7^{*} \\
(24.5)\end{array}$ & $\begin{array}{r}310.6^{*} \\
(25.5)\end{array}$ \\
\hline National contexts & 20 & 20 & 20 & 22 \\
\hline Elections & 166 & 166 & 166 & 179 \\
\hline
\end{tabular}

Method: Flanders and Wallonia in Belgium were considered two distinct national contexts; the same goes for Presidential and midterm elections in the US. Results were produced with the brms package for R (Bürkner, 2017), version 2.15.0. Parameters are summarized based on a sample of 15,000 draws from the posterior distribution. Each model was run using 3 chains, for a period of 100,000 iterations, with a burn-in period of 95,000 iterations. The models relied on weakly informative priors: $\mathcal{N}(0,2.5)$.

Notes: Standard errors in brackets. ' $*$ ' indicates that the $90 \%$ credible interval does not intersect 0 . 
TABLE 7: Additional sensitivity checks for unified specification

\begin{tabular}{|c|c|c|}
\hline & Model 5 & Model 6 \\
\hline Leg. fractionalization & $\begin{array}{c}0.084 \\
(0.096)\end{array}$ & $\begin{array}{c}0.059 \\
(0.096)\end{array}$ \\
\hline Polarization (RILE) & $\begin{array}{c}-0.161 \\
(0.118)\end{array}$ & $\begin{array}{c}-0.139 \\
(0.124)\end{array}$ \\
\hline Income inequality & $\begin{array}{c}-0.109 \\
(0.108)\end{array}$ & $\begin{array}{c}-0.080 \\
(0.111)\end{array}$ \\
\hline Left party shifts (RILE) & $\begin{array}{c}0.003 \\
(0.117)\end{array}$ & $\begin{array}{c}0.077 \\
(0.125)\end{array}$ \\
\hline Union density & $\begin{array}{r}-0.264^{*} \\
(0.118)\end{array}$ & $\begin{array}{r}-0.269^{*} \\
(0.124)\end{array}$ \\
\hline VAP turnout & $\begin{array}{r}-0.262^{*} \\
(0.107)\end{array}$ & $\begin{array}{r}-0.238^{*} \\
(0.110)\end{array}$ \\
\hline Compulsory voting & $\begin{array}{r}-0.436 \\
(0.281)\end{array}$ & $\begin{array}{r}-0.503^{*} \\
(0.276)\end{array}$ \\
\hline Federal system & $\begin{array}{r}0.351^{*} \\
(0.194)\end{array}$ & $\begin{array}{c}0.314 \\
(0.196)\end{array}$ \\
\hline Mean dist. magnitude & $\begin{array}{c}0.252 \\
(0.182)\end{array}$ & $\begin{array}{c}0.282 \\
(0.180)\end{array}$ \\
\hline Political corruption & $\begin{array}{c}0.011 \\
(0.219)\end{array}$ & \\
\hline Societal polarization & & $\begin{array}{c}0.216 \\
(0.200)\end{array}$ \\
\hline (Intercept) & $\begin{array}{r}1.167^{*} \\
(0.088)\end{array}$ & $\begin{array}{r}1.165^{*} \\
(0.088)\end{array}$ \\
\hline$\sigma$ intercept & $\begin{array}{c}0.240^{*} \\
(0.111)\end{array}$ & $\begin{array}{r}0.219^{*} \\
(0.115)\end{array}$ \\
\hline Residual & $\begin{array}{r}0.440^{*} \\
(0.039)\end{array}$ & $\begin{array}{c}0.434^{*} \\
(0.039)\end{array}$ \\
\hline$\rho(\mathrm{AR} 1)$ & $\begin{array}{r}0.430^{*} \\
(0.153)\end{array}$ & $\begin{array}{c}0.485^{*} \\
(0.140)\end{array}$ \\
\hline ELPD & $\begin{array}{r}-155.8^{*} \\
(12.8)\end{array}$ & $\begin{array}{r}-144.4^{*} \\
(12.6)\end{array}$ \\
\hline LOO IC & $\begin{array}{r}311.5^{*} \\
(25.6)\end{array}$ & $\begin{array}{r}288.8^{*} \\
(25.3)\end{array}$ \\
\hline National contexts & 22 & 21 \\
\hline Elections & 179 & 171 \\
\hline
\end{tabular}

Method: Flanders and Wallonia in Belgium were considered two distinct national contexts; the same goes for Presidential and midterm elections in the US. Results were produced with the brms package for R (Bürkner, 2017), version 2.15.0. Parameters are summarized based on a sample of 15,000 draws from the posterior distribution. Each model was run using 3 chains, for a period of 100,000 iterations, with a burn-in period of 95,000 iterations. The models relied on weakly informative priors: $\mathcal{N}(0,2.5)$.

Notes: Standard errors in brackets. ' $*$ ' indicates that the $90 \%$ credible interval does not intersect 0 . 
TABLE 8: Frequentist estimates for main results in manuscript: resources, motivation, mobilization, and unified specifications

\begin{tabular}{|c|c|c|c|c|}
\hline & Model 1 & Model 2 & Model 3 & Model 4 \\
\hline Leg. fractionalization & $\begin{array}{l}0.313^{* * *} \\
(0.104)\end{array}$ & & & $\begin{array}{l}0.225^{* *} \\
(0.113)\end{array}$ \\
\hline Polarization (RILE) & $\begin{array}{c}-0.212^{* *} \\
(0.101)\end{array}$ & & & $\begin{array}{c}-0.127 \\
(0.138)\end{array}$ \\
\hline Income inequality & & $\begin{array}{c}0.031 \\
(0.114)\end{array}$ & & $\begin{array}{c}-0.154 \\
(0.136)\end{array}$ \\
\hline Left party shifts (RILE) & & $\begin{array}{c}0.083 \\
(0.112)\end{array}$ & & $\begin{array}{c}0.153 \\
(0.152)\end{array}$ \\
\hline Right party shifts (RILE) & & $\begin{array}{c}0.092 \\
(0.107)\end{array}$ & & \\
\hline Union density & & & $\begin{array}{c}-0.171 \\
(0.107)\end{array}$ & $\begin{array}{c}-0.365^{* *} \\
(0.143)\end{array}$ \\
\hline Associational engagement & $\begin{array}{c}0.033 \\
(0.215)\end{array}$ & & & $\begin{array}{c}-0.082 \\
(0.230)\end{array}$ \\
\hline Prog. party competition & & & $\begin{array}{c}0.005 \\
(0.194)\end{array}$ & $\begin{array}{c}0.165 \\
(0.226)\end{array}$ \\
\hline Compulsory voting & $\begin{array}{r}-0.528^{*} \\
(0.285)\end{array}$ & $\begin{array}{c}-0.549^{* *} \\
(0.258)\end{array}$ & $\begin{array}{c}-0.608^{* *} \\
(0.273)\end{array}$ & $\begin{array}{c}-0.489 \\
(0.284)\end{array}$ \\
\hline $\begin{array}{l}\text { Federal system } \\
\text { (Intercept) }\end{array}$ & $\begin{array}{l}0.299 \\
(0.234) \\
1.155^{* * *} \\
(0.099)\end{array}$ & $\begin{array}{c}0.204 \\
(0.188) \\
1.209^{* * *} \\
(0.087)\end{array}$ & $\begin{array}{c}0.274 \\
(0.192) \\
1.224^{* * *} \\
(0.091)\end{array}$ & $\begin{array}{l}0.212 \\
(0.235) \\
1.185^{* * *} \\
(0.097)\end{array}$ \\
\hline AIC & 383.933 & 415.317 & 438.124 & 372.438 \\
\hline $\mathrm{BIC}$ & 412.155 & 443.852 & 464.226 & 412.086 \\
\hline Log Likelihood & -182.966 & -198.659 & -211.062 & -173.219 \\
\hline National contexts & 21 & 22 & 23 & 20 \\
\hline Elections & 176 & 182 & 198 & 166 \\
\hline
\end{tabular}

${ }^{* * *} p<0.01 ;{ }^{* *} p<0.05 ;{ }^{*} p<0.1$. Specifications estimated with the nlme package; AR(1) correlation structure specified for the level-1 residuals. 
TABLE 9: Sensitivity checks using fixed-effects specifications

\begin{tabular}{|c|c|c|c|c|}
\hline & Model 1 & Model 2 & Model 3 & Model 4 \\
\hline Leg. fractionalization & $\begin{array}{c}0.169^{*} \\
(0.092)\end{array}$ & & & $\begin{array}{c}0.149 \\
(0.094)\end{array}$ \\
\hline Polarization (RILE) & $\begin{array}{r}-0.146 \\
(0.092)\end{array}$ & & & $\begin{array}{c}-0.170 \\
(0.121)\end{array}$ \\
\hline Income inequality & & $\begin{array}{c}0.011 \\
(0.117)\end{array}$ & & $\begin{array}{r}-0.080 \\
(0.113)\end{array}$ \\
\hline Left party shifts (RILE) & & $\begin{array}{c}0.097 \\
(0.100)\end{array}$ & & $\begin{array}{c}-0.012 \\
(0.119)\end{array}$ \\
\hline Right party shifts (RILE) & & $\begin{array}{r}-0.005 \\
(0.103)\end{array}$ & & \\
\hline Union density & & & $\begin{array}{r}-0.220^{*} \\
(0.110)\end{array}$ & $\begin{array}{r}-0.329^{*} \\
(0.123)\end{array}$ \\
\hline (Intercept) & $\begin{array}{l}1.063^{*} \\
(0.309)\end{array}$ & $\begin{array}{r}1.080^{*} \\
(0.347)\end{array}$ & $\begin{array}{c}1.039^{*} \\
(0.310)\end{array}$ & $\begin{array}{r}1.068^{*} \\
(0.306)\end{array}$ \\
\hline Residual & $\begin{array}{c}0.462^{*} \\
(0.039)\end{array}$ & $\begin{array}{c}0.472^{*} \\
(0.042)\end{array}$ & $\begin{array}{c}0.439^{*} \\
(0.037)\end{array}$ & $\begin{array}{r}0.454^{*} \\
(0.040)\end{array}$ \\
\hline$\rho(\mathrm{AR} 1)$ & $\begin{array}{c}0.566^{*} \\
(0.133)\end{array}$ & $\begin{array}{c}0.651^{*} \\
(0.133)\end{array}$ & $\begin{array}{c}0.621^{*} \\
(0.130)\end{array}$ & $\begin{array}{r}0.577^{*} \\
(0.139)\end{array}$ \\
\hline ELPD & $\begin{array}{r}-172.6^{*} \\
(13.3)\end{array}$ & $\begin{array}{r}-165.6^{*} \\
(13.3)\end{array}$ & $\begin{array}{r}-170.6^{*} \\
(14.0)\end{array}$ & $\begin{array}{r}-161.6^{*} \\
(13.0)\end{array}$ \\
\hline LOO IC & $\begin{array}{r}345.2^{*} \\
(26.6)\end{array}$ & $\begin{array}{r}331.3^{*} \\
(26.6)\end{array}$ & $\begin{array}{r}341.2^{*} \\
(28.1)\end{array}$ & $\begin{array}{r}323.2^{*} \\
(26.0)\end{array}$ \\
\hline Elections & 194 & 182 & 198 & 182 \\
\hline
\end{tabular}

Method: Flanders and Wallonia in Belgium were considered two distinct national contexts; the same goes for Presidential and midterm elections in the US. Results were produced with the brms package for R (Bürkner, 2017), version 2.15.0. Parameters are summarized based on a sample of 15,000 draws from the posterior distribution. Each model was run using 3 chains, for a period of 100,000 iterations, with a burn-in period of 95,000 iterations. The models relied on weakly informative priors: $\mathcal{N}(0,2.5)$.

Notes: Standard errors in brackets. '*' indicates that the $90 \%$ credible interval does not intersect 0 . 


\section{Model Fit Assessment}

The panels in Figure 3 display a few posterior predictive checks (Gelman, Meng, \& Stern, 1996) for the unified specification from Table 2 in the manuscript. A good model should accurately be able to reproduce features of the actual outcome variable, such as its distribution, its mean, as well as its minimum and maximum value. Overall, the model succeeds in reproducing the distribution of the turnout gap (panel 3a); it also manages, on average, to predict the mean turnout gap (panel 3b). On the other hand, the unified specification clearly does not do so well in predicting the tails of the distribution of the outcome variable: it consistently overestimates the minimum (panel $3 \mathrm{c}$ and $3 \mathrm{~d}$ ). Even though the accuracy in predicting the maximum value in the data is better, in both cases the precision is very low, judging by the spread of the predictions. In panel $3 \mathrm{e}$ I plot simulated values of the turnout gap against the actual values in the data, for 3 replications of the model. It is clear that errors of prediction of considerable magnitude sometimes occur. While instructive, the model needs further improvement. 
FIGURE 3: Bayesian predictive checks for unified model in Table 2 from the manuscript

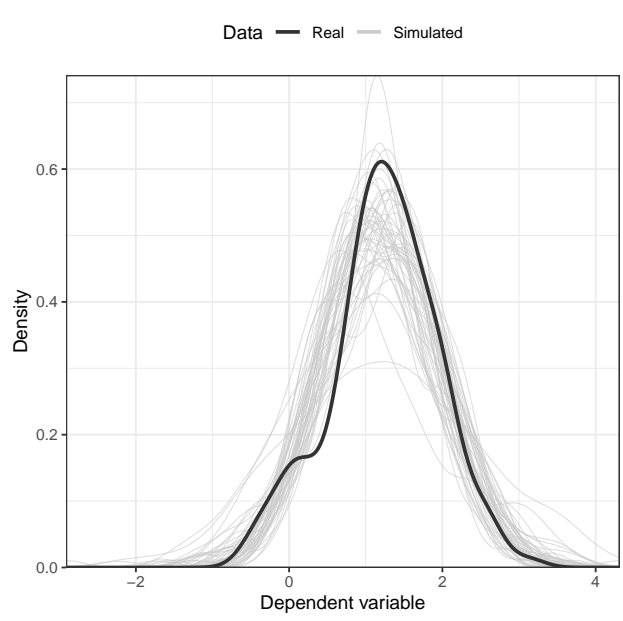

(A) Replicating the DV

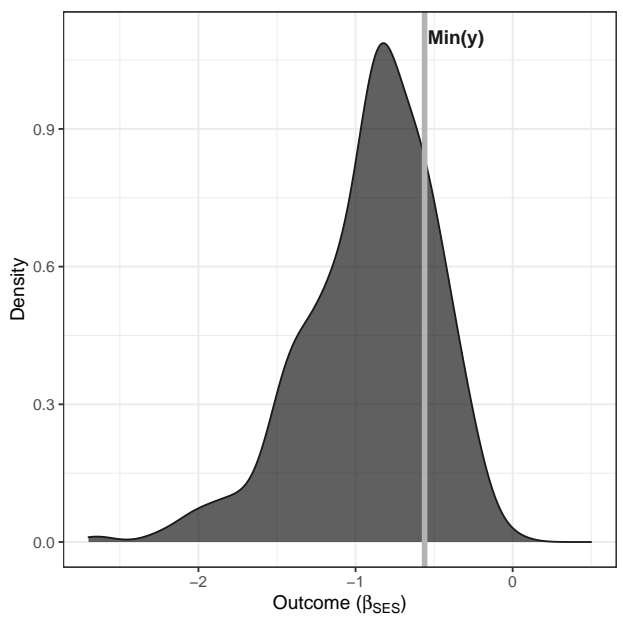

(C) Replicating the minimum

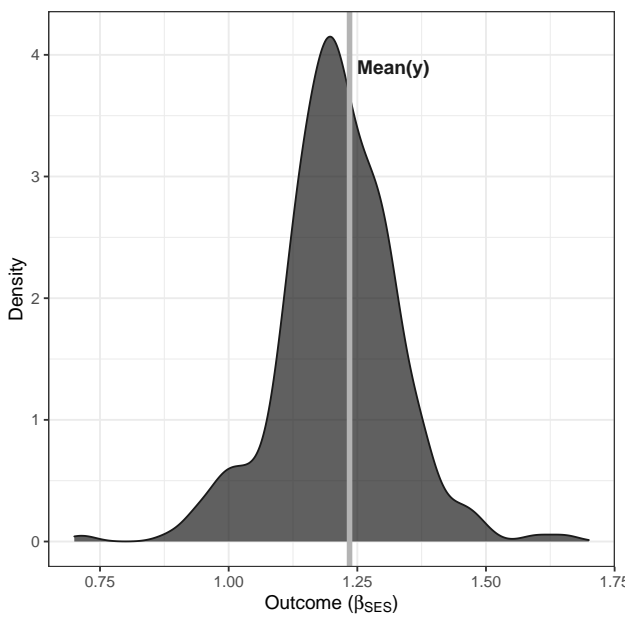

(B) Replicating the mean

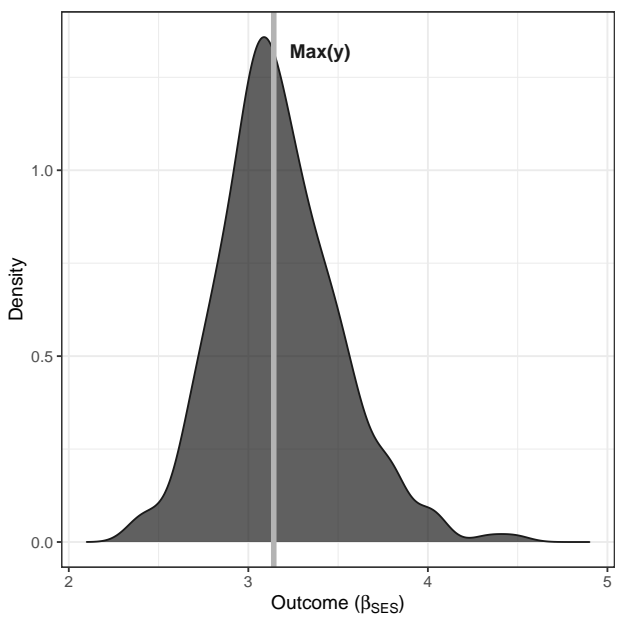

(D) Replicating the maximum
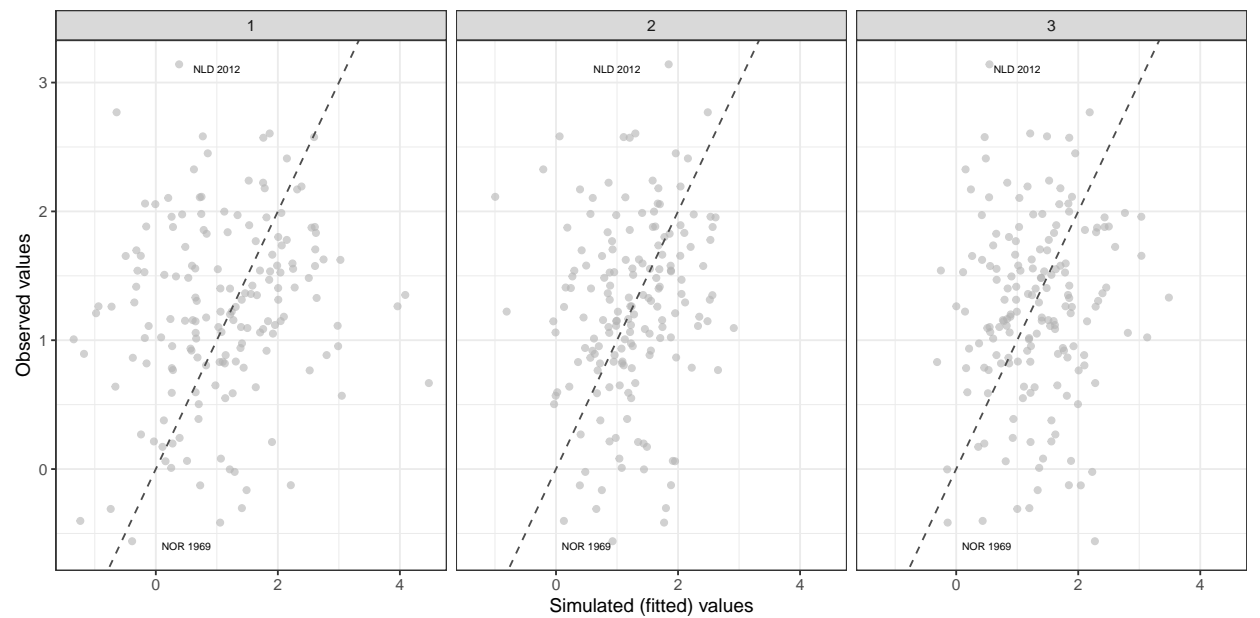

(E) Simulated vs. actual 


\section{References}

Armingeon, K., Wenger, V., Wiedemeier, F., Isler, C., Knöpfel, L., Weisstanner, D., \& Engler, S. (2020). Comparative Political Data Set, 1960-2018. Bern: Institute of Political Science, University of Bern.

Budge, I., Klingemann, H.-D., Volkens, A., \& Bara, J. (2001). Mapping Policy Preferences. Estimates for Parties, Electors, and Governments 1945-1998. Oxford: Oxford University Press.

Bürkner, P.-C. (2017). brms: An R Package for Bayesian Multilevel Models Using Stan. Journal of Statistical Software, 80(1), 1-28.

Coppedge, M., Gerring, J., Knutsen, C. H., Lindberg, S. I., Teorell, J., Alizada, N., ... Ziblatt, D. (2020). V-Dem [Country-Year/Country-Date] Dataset v11.1. University of Gothenburg: Varieties of Democracy (V-Dem) Project.

Cruz, C., Keefer, P., \& Scartascini, C. (2020). Database of Political Institutions 2020 (DPI2020). Washington, D.C.: Inter-American Development Bank.

Gelman, A., Meng, X.-L., \& Stern, H. (1996). Posterior Predictive Assessment of Model Fitness via Realized Discrepancies. Statistica Sinica, 6(4), 733-760.

Jansen, G., Evans, G., \& De Graaf, N. D. (2013). Class Voting and Left-Right Party Positions: A Comparative Study of Fifteen Western Democracies, 1960-2005. In Political Choice Matters: Explaining the Strength of Class and Religious Cleavages in Cross-National Perspective (pp. 46-86). Oxford: Oxford University Press.

Klingemann, H.-D., Volkens, A., Bara, J., Budge, I., \& McDonald, M. D. (2006). Mapping Policy Preferences II. Estimates for Parties, Electors, and Governments in Eastern Europe, the European Union and the OECD, 1990-2003. Oxford: Oxford University Press.

Krause, W., Lehmann, P., Theres, M., Merz, N., Regel, S., \& Weßels, B. (2020). The Manifesto Data Collection: South America. Version 2020b. Berlin: Wissenschaftszentrum Berlinfür Sozialforschung. Retrieved from https://doi.org/10.25522/manifesto . mpdssa.2020b

Laakso, M., \& Taagepera, R. (1979). "Effective" Number of Parties: A Measure with Application to West Europe. Comparative Political Studies, 12(1), 3-27.

Leighley, J. E., \& Nagler, J. (2007). Unions, Voter Turnout, and Class Bias in the U.S. Electorate, 1964-2004. The Journal of Politics, 69(02).

Matsubayashi, T., \& Sakaiya, S. (2020). Income Inequality and Income Bias in Voter Turnout. European Journal of Political Economy, 101966. doi: 10.1016/j.ejpoleco.2020.101966

OECD. (2005). Education at a Glance: OECD Indicators 2005 (Tech. Rep.). Paris: Organization for Economic Cooperation and Development.

Schmitt, H., Önnudóttir, E. H., Teperoglou, E., \& Vegetti, F. (2013). The True European Voter: Micro Data Codebook. Mannheim University: Mannheimer Zentrum für Europäische Sozialforschung.

Scruggs, L., Jahn, D., \& Kuitto, K. (2018). Comparative Welfare Entitlements Data Set 2, Version 2018-12. University of Connecticut / University of Greifswald. Retrieved from http: / / cwed2.org/

Solt, F. (2008). Economic Inequality and Democratic Political Engagement. American Journal of Political Science, 52(1), 48-60. 
Solt, F. (2020). Measuring Income Inequality Across Countries and Over Time: The Standardized World Income Inequality Database. Social Science Quarterly, 101(3), 1183-1199.

Taylor, M., \& Herman, V. M. (1971). Party Systems and Government Stability. The American Political Science Review, 65(1), 28-37.

Volkens, A., Burst, T., Krause, W., Lehmann, P., Matthieß, T., Merz, N., ... Zehnter, L. (2020). The manifesto data collection. manifesto project ( $\mathrm{mrg} / \mathrm{cmp} /$ marpor). version 2020b. Berlin: Wissenschaftszentrum Berlin für Sozialforschung. Retrieved from https: / / doi . org / 10.25522 /manifesto.mpds.2020b doi: 10.25522/manifesto.mpds.2020b 